UNIVERSIDAD DE LOS ANDES

\title{
Modeling and Impacts of Plug-in Electric Vehicles in Residential Distribution Systems with Coordinated Charging Schemes
}

\author{
by \\ Sergio Zambrano Perilla
}

A thesis submitted in partial fulfillment for the degree of

M.Sc. in Electrical Engineering

in

Faculty of Engineering

Department of Electrical and Electronics Engineering

August 14, 2015 


\section{Declaration of Authorship}

I, Sergio Zambrano Perilla, declare that this thesis titled, 'Modeling and Impacts of Plug-in Electric Vehicles in Residential Distribution Systems with Coordinated Charging Schemes' and the work presented in it are my own. I confirm that:

- This work was done wholly or mainly while in candidature for a research degree at this University.

- Where any part of this thesis has previously been submitted for a degree or any other qualification at this University or any other institution, this has been clearly stated.

- Where I have consulted the published work of others, this is always clearly attributed.

- Where I have quoted from the work of others, the source is always given. With the exception of such quotations, this thesis is entirely my own work.

- I have acknowledged all main sources of help.

- Where the thesis is based on work done by myself jointly with others, I have made clear exactly what was done by others and what I have contributed myself.

Signed:

Date: 


\title{
UNIVERSIDAD DE LOS ANDES
}

\author{
Abstract \\ Faculty of Engineering \\ Department of Electrical and Electronics Engineering \\ M.Sc. in Electrical Engineering \\ by Sergio Zambrano Perilla
}

This work proposes a modeling methodology for implementation of a charging infrastructure of Plug-in Electric Vehicles (PEVs) within residential distribution systems. Using the feeder daily models, driving patterns, PEVs penetration and charging characteristics; the impact of their connection in the Power Distribution Network (PDN) is determined. The number and distribution of PEVs in a residential distribution network is modeled and applied to the IEEE 13-node test feeder. Then, a coordinated charging scheme for PEVs is proposed in order to minimize overloading and undervoltage events in the network, and also to perform peak load shaving through the means of load shifting, by delaying the start charging time of PEVs to off peak hours. Finally, impacts such as change in feeder demand curves, voltage deviation, element overloading, electrical losses and voltage unbalance, are addressed; taking into account the coordinated charging schemes proposed. 


\section{Acknowledgements}

My special thanks goes to Gustavo Ramos for taking on this thesis work.

Advice given by David Celeita and Davis Montenegro has been a great help in developing the simulation model and using of DSSim-PC during this work.

I am particularly grateful for the support and good times given by my friends.

To my beloved girlfriend for all her patience and support.

To my mother and my family, I will always be grateful... 


\section{Contents}

Declaration of Authorship

Abstract

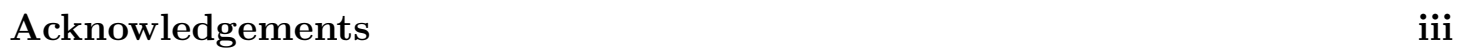

List of Figures vi vi v v vis

List of Tables vii

$\begin{array}{lll}1 & \text { Introduction } & 1\end{array}$

$\begin{array}{lll}2 & \text { Objectives } & 3\end{array}$

$2.1 \quad$ General Objective $\ldots \ldots \ldots \ldots \ldots \ldots$

2.2 Specific Objectives . . . . . . . . . . . . . . . . . . 3

$\begin{array}{|lll|}3 & \text { Concepts of Plug-in Electric Vehicles Impact } & 4\end{array}$

\begin{tabular}{|lr}
\hline & Plug-in Electric Charging Model
\end{tabular}

4.1 Existing Load Profiles . . . . . . . . . . . . . . . . . . . . . . . . . . . . . 6

4.2 PEV Model and Battery Capacity . . . . . . . . . . . . . . . . . . . . . . . . . . . . . .

4.3 Start Charging Time $\ldots \ldots \ldots \ldots \ldots \ldots$

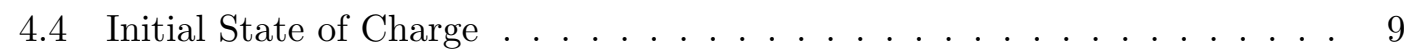

$4.5 \quad$ Charging Level $\ldots \ldots \ldots \ldots$

4.6 PEV Penetration Level and Load Growth . . . . . . . . . . . . . . . . . . 10

$4.7 \quad$ Number of Vehicles per House and PEV Distribution . . . . . . . . . . . . 11

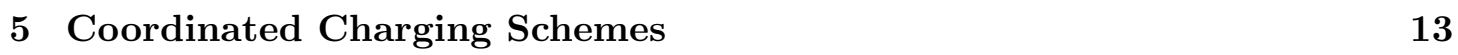

6 Simulation Parameters 16

$6.1 \quad$ System Description and Computer Tools . . . . . . . . . . . . . . . . . . . . 16

6.2 Test Cases Definition . . . . . . . . . . . . . . . . . . . . . . . 18

\begin{tabular}{|ll|}
7 & Plug-in Electric Vehicles Model Implementation \\
\hline
\end{tabular}

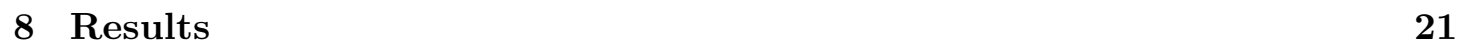

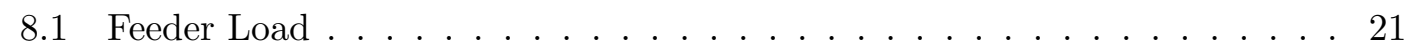

8.2 Voltage Deviation $\ldots \ldots \ldots \ldots \ldots \ldots \ldots \ldots$ 
8.3 Elements Overloading and Peak Shaving . . . . . . . . . . . . . . . . . . 23

$8.4 \quad$ Electrical Losses $\ldots \ldots \ldots \ldots$. . . . . . . . . . . . . . . . . . . . . 25

8.5 Voltage Unbalance $\ldots \ldots \ldots \ldots \ldots$. . . . . . . . . . . . . . . 26

\begin{tabular}{llr}
\hline 9 & Conclusions & 27
\end{tabular}

\begin{tabular}{lr}
\hline Bibliography & 28
\end{tabular}

\begin{tabular}{ll}
\hline Appendices & 31
\end{tabular} 


\section{List of Figures}

4.1 IEEE 13 node test feeder. . . . . . . . . . . . . . . . . . . 7

$4.2 \quad$ IEEE 13 node test average daily feeder demand curve. . . . . . . . . . . . 7

$4.3 \quad$ Probability distribution of start charging time (EPRI). . . . . . . . . . . . 8

$4.4 \quad$ Average daily driving distance of vehicles (NHTS 2009). . . . . . . . . . . 9

$4.5 \quad$ PEV penetration scenarios between 2010 and 2030 (EPRI). . . . . . . . . 11

$5.1 \quad$ Coordinated charging scheme for undervoltage mitigation. . . . . . . . . . 14

5.2 Coordinated charging scheme for overload mitigation. . . . . . . . . . 15

$6.1 \quad$ IEEE 13 node test feeder with PEVs implemented in DSSim-PC. . . . . . 17

$7.1 \quad$ PEV Management System implemented in LabView. . . . . . . . . . . . . 20

7.2 PEV Management System schematic implementation in LabView. . . . . 20

8.1 PDN average daily feeder demand curve for each test case. . . . . . . . . . 22

8.2 Bus 675 average daily voltage profile for each test case. . . . . . . . . . . . . 23

8.3 Bus 675 typical voltage profile during two days. . . . . . . . . . . . . 23

8.4 Transformer XFM-1 average daily load profile for each test case. . . . . . 24

8.5 Transformer XFM-1 typical load profile during two days. . . . . . . . . . . 25

$8.6 \quad$ Average daily electrical losses for each test case. . . . . . . . . . . . . 25

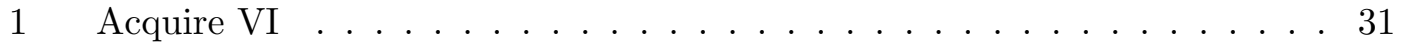

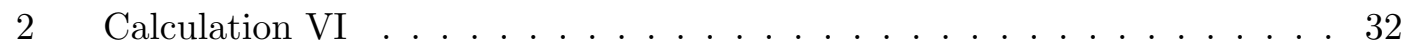

3 Connect VI . . . . . . . . . . . . . . . . . . . . . . . . . . . 32

$4 \quad$ Controller VI $\ldots \ldots \ldots \ldots \ldots \ldots$

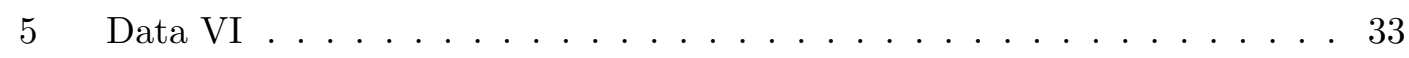

$6 \quad$ Decision VI . . . . . . . . . . . . . . . . . . . . . . . . . . . . . 34

7 Display VT . . . . . . . . . . . . . . . . . . 34

$8 \quad$ EV Arrival VI . . . . . . . . . . . . . . . . . . . . . . . . 35

$9 \quad$ EV Distance VI . . . . . . . . . . . . . . . . . . . . . . 35

10 Model VI . . . . . . . . . . . . . . . . . . . . . . . . . . . 36

11 Powers VI . . . . . . . . . . . . . . . . . . . . . . . . . . 36

12 Status VI . . . . . . . . . . . . . . . . . . . . . . . 37

13 Time VI . . . . . . . . . . . . . . . . . . . . . . 37

14 Time Adjust VI . . . . . . . . . . . . . . . . . . . . 37

15 Time Format VI $\ldots \ldots \ldots \ldots \ldots \ldots$

16 Voltages VI $\ldots \ldots \ldots \ldots \ldots \ldots \ldots$

17 Write VI . . . . . . . . . . . . . . . . . . . . 38 


\section{List of Tables}

$4.1 \quad$ Percentage of houses with different number of vehicles. . . . . . . . . . . . 12

$4.2 \quad$ Percentage of each type of vehicle in NHTS 2009. . . . . . . . . . . . . . 12

4.3 Number of PEVs connected to each bus in IEEE 13 node test feeder with $21 \%$ penetration level. . . . . . . . . . . . . . . 12

$8.1 \quad$ Feeder load data comparison. . . . . . . . . . . . . . . . . . . . . 22

8.2 Transformer XFM-1 loading data comparison. . . . . . . . . . . . . . . . . 24

$8.3 \quad$ Average voltage unbalance at Bus 650. . . . . . . . . . . . . . 26 


\section{Chapter 1}

\section{Introduction}

In recent years, there has been a growing interest in the development and implementation of transportation alternatives to traditional Internal Combustion (IC) vehicles, with both environmental and economic objectives. Plug-in Electric Vehicles (PEV) and HybridElectric Vehicles (HEV) offer advantages in terms of reducing emissions of greenhouse gases (GHG), reducing dependence on fossil fuels, achieving greater energy efficiency and increasing fuel economy for users. These vehicles have a battery storage system, means of recharging the battery from an external source, and the ability to drive in all-electric mode [1]. Different automotive companies have begun to incorporate PEVs and HEVs in their research, development and production. Models such as the Toyota Prius, Chevrolet Volt, Cooper Mini E, Fisker Karma, Nissan Leaf and Tesla Roadster, are evidence of this trend by manufacturers.

Given this new scenario, the impacts, economic costs and benefits achieved from the implementation of these vehicles for both consumers and producers, have been analyzed extensively. However, it is also necessary to conduct a study to identify in advance the effect of connecting these PEVs and HEVs on the existing Power Distribution Networks (PDN), taking into account the new loads that must be attended as well as their characteristics. Studies conducted by the Electric Power Research Institute (EPRI) in the United States, have shown that if half of the vehicles in the year 2050 are replaced by Electric Vehicles (EV), an increase of only $8 \%$ in generation capacity is required [2]. In this regard, the National Renewable Energy Laboratory (NREL) has concluded that large-scale deployment of these vehicles will have very few negative effects on the requirements of power generation [3].

Different authors suggest a number of methodologies, metrics, scenarios and test cases to analyze some indicators related to the impact of the connection of PEVs and HEVs to the network. For example, deterministic or stochastic methods can be performed 
to characterize the behavior of the users, including their patterns of use of EVs as well as the way they recharge them. When defining different scenarios and test cases, the authors have taken into account elements such as the percentage of penetration of EVs in the PDN, the characteristics of chargers installed by the users and their behavior, the topology of the existing systems and the distribution of these new charges in them. Moreover, the metrics or indicators that are typically used to assess the impact of the connection of EVs include factors such as voltage deviation, load profile and peak load of the distribution networks, imbalances between phases, overloading of existing transformers, total losses in the grid, and indicators of reliability at the distribution level.

Therefore, it is up to each author choosing which of the aspects previously presented will be taken into account when making the assessment of the impact of EVs on the distribution system, in accordance with their objectives. Ideally, it would cover those with the greatest impact for both consumers and network operators. Similarly, the quality and validity of the results can be improved depending on the use of appropriate computer tools, which allow the development of more accurate and comprehensive models of EVs connection in the current PDNs. The organization of the paper is as follows: concepts of PEVs impact are presented in Chapter 3. The PEV charging model is described in Chapter 4 . Chapter 5 addresses the coordinated charging schemes proposed, while the simulation parameters are defined in Chapter 6. Finally, implementation and test results are presented in Chapters 7 and 8 , and a concluding remark is given. 


\section{Chapter 2}

\section{Objectives}

\subsection{General Objective}

To perform an assessment of the impact of plug-in electric vehicles in the power distribution networks, by proposing a methodology including scenarios, metrics, test cases and objectives; in order to perform a complete analysis of their impacts in the power system. Afterwards, to propose a coordinated charging scheme that allows mitigation of the impacts previously detected, by using the available computer tools and concepts of distribution management systems.

\section{$2.2 \quad$ Specific Objectives}

- To identify and to define the impact of plug-in electric vehicles in the power distribution networks, based on adequate scenarios, metrics and objectives.

- To propose an impact assessment methodology, taking into account the plug-in electric vehicles characteristics defined, as well as the available computer tools and test cases.

- To develop a coordinated charging scheme of plug-in electric vehicles in order to mitigate the impacts associated with their connection to the power distribution network. 


\section{Chapter 3}

\section{Concepts of Plug-in Electric Vehicles Impact}

As previously mentioned, the installation of PEVs will have a negative effect on the existing PDNs, affecting various factors related to the installed equipment, the operation costs and the quality of the electricity supplied to users [1, 4 9]. In this regard, the installation of new loads in the residential PDN can lead to overloading of the current distribution transformers, reducing their operational lifetime [7]. Similarly, there is evidence proving that the current THD can affect the operation of protection elements, so the inclusion of EV chargers may affect previously installed equipment [5]. Electrical losses should also be recalculated considering the inclusion and penetration of chargers in the PDN, in addition to their distribution according to the topology of existing systems. Finally, it is necessary to consider how these new loads will affect the power quality provided to users; including voltage deviations and phase unbalances [1, 5].

In order to adequately assess these future impacts, it is necessary to define a series of scenarios that take into account different panoramas of connection of these new chargers. First, the behavior of users and their routine utilization of EVs is established, for which consumer and car driving habits surveys are used [4, 10, 11]. These patterns are also used to determine, statistically, at what times of the day drivers choose to charge their vehicles, thus establishing how the daily load profile of existing residential PDNs is going to be modified [1]. In addition to this, approaches to the penetration percentage of EVs in the coming years are realized, so that it approximates the way in which the installation of this infrastructure will affect the existing loads [5, 12 14]. At this point it should be noted that, alongside the inclusion of EVs in the system, the existing load has its own increase rate, so expansion scenarios may include both effects [4, 15]. 
Additionally, the authors have attempted to develop models and comparisons to evaluate procedures of coordinated charging. These schemes are developed in order to mitigate the electrical impacts caused by the connection of EVs, or to enhance the system operation. Thus, by creating management models, a "smart" EV charging is performed in order to avoid the occurrence of significant peaks in their load profiles, or to improve aspects such as the load factor of the distribution circuits within a PDN, defined as the ratio of the average demand to the maximum demand [14, 16-18]. These methodologies, whereby the assessment of impacts associated with each scenario is performed, can be deterministic, stochastic or a combination of both [7, 15, 16]. Different assumptions are made in each case, regarding the model related to driving behaviors and charging patterns of users, as well as the distribution of EVs into existing PDNs.

As computer tools have allowed to, different applications have been developed in order to assess more accurately certain phenomena in the grid [10]. For example, looking at electric vehicles as potential energy storage elements connected to the network, a concept known as Vehicle-To-Grid (V2G) [1, including its operation and control schemes, it has been analyzed how it is possible to have benefits from their ability to deliver electricity to the grid, considering a Real-Time (RT) framework [19]. Similarly, coordinated charging previously mentioned can be established in RT environments, including their model, control and operation [20]. It can be seen how the possibility of having these tools and applications, allow the use of more comprehensive models that require significant computing capabilities, which will translate into better results and analysis. 


\section{Chapter 4}

\section{Plug-in Electric Charging Model}

Below, each of the parameters to be taken into account by the proposed model and the way they are addressed, shall be defined. A selection of these parameters coincides with the antecedents found during the literature review. Approximations made to each one of them, aim to develop a model as complete as possible, taking into account the objectives of the project, the resources available and relevance in the context of a Distribution Management System (DMS).

\subsection{Existing Load Profiles}

Firstly, when developing a model for conducting the study of impacts, it is necessary to determine the existing load profiles in each of the nodes (corresponding to residential, commercial and industrial users), and how these loads vary over time. The classic approach in this respect is to use typical curves according to the types of RCI users. Load curves represent typical power consumption habits of different types of consumers grouped according to each sector. Thus, it is possible to construct demand curves for different consumers by having the information for their activity. As this assessment focuses on residential distribution systems, the existing demand curves will coincide with the typical for any residential feeder. Finally, it is necessary to define the feeder in which the study will be implemented. Considering test systems used by most authors, its initial implementation is proposed in the IEEE 13 node test feeder, shown in Fig.4.1, modified to include PEVs [21]. Accordingly, Fig 4.2 depicts the average daily load profile for the defined test system, given 365 days of data. It is worth adding that, given the scalability of the proposed model, it is possible to perform its implementation in larger systems. 


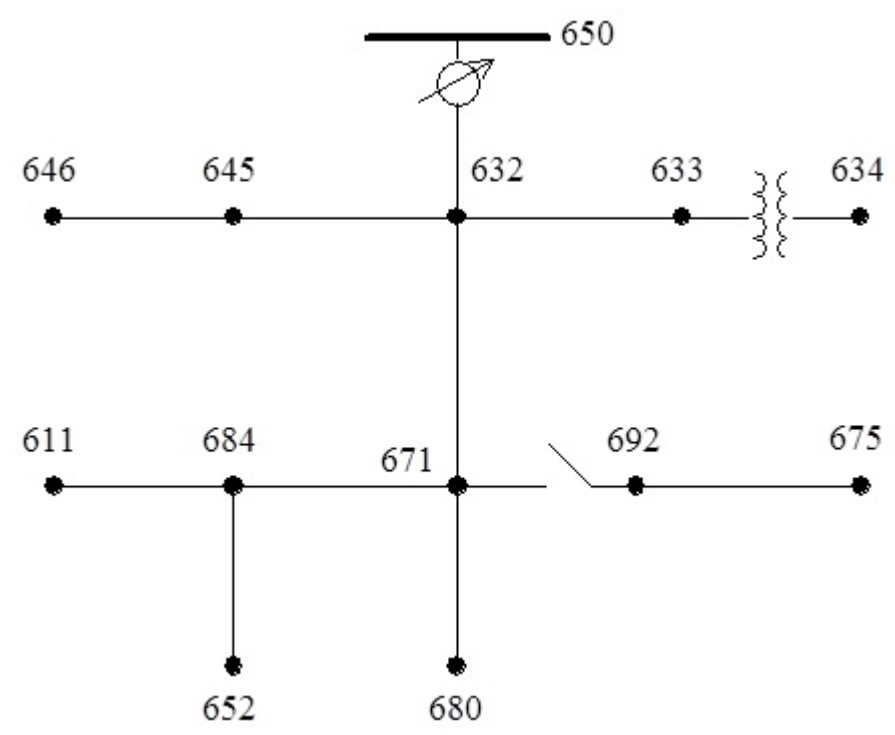

FIGURE 4.1: IEEE 13 node test feeder [21].

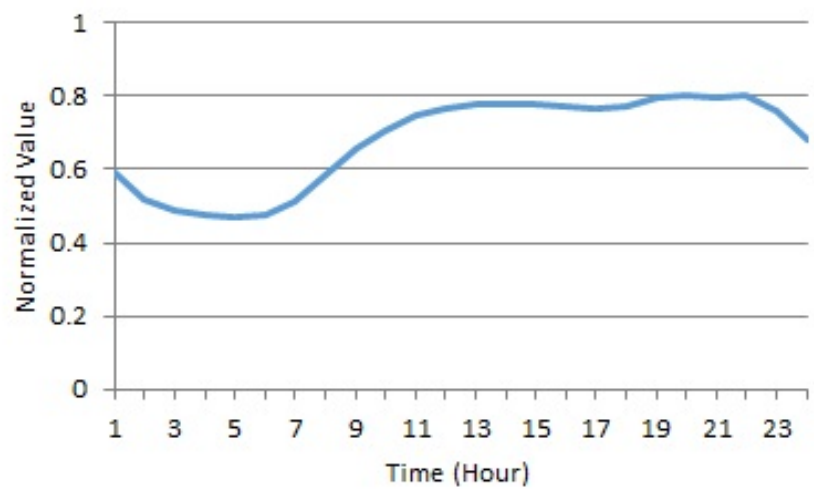

FIGURE 4.2: IEEE 13 node test average daily feeder demand curve.

\subsection{PEV Model and Battery Capacity}

The capacity of the battery allows determination of the maximum distance range of a $\mathrm{PEV}$, as well as the energy required to charge it. In order to evaluate the impact of PEV charging on the distribution system, all the test cases in this paper are carried out considering Nissan Leaf PEVs [22]. This was the first mass-produced battery electric vehicle in the U.S. market. As of March 2015, Nissan had delivered more than 75,000 units since its introduction, becoming the all-time top selling PEV in the United States 23. With $24 \mathrm{kWh}$ batteries, and average fuel efficiency of $0.198 \mathrm{kWh} / \mathrm{km}$, these vehicles allow a maximum range of $121 \mathrm{~km}(75 \mathrm{mi})$. 


\subsection{Start Charging Time}

Upon making the study of the impact of the connection of PEVs, it should be noted in particular that they are subject to their use by drivers. It is therefore necessary to make a proper approach with respect to the pattern of use of the vehicles for each day of the week. By taking into account these driving habits, it is possible to determine at what time of the day vehicles arrive home to be charged and, therefore, how do they affect existing daily load profiles.

In this regard, different types of transport studies have been conducted, for example, in the United States, by entities such as the Electric Power Research Institute (EPRI), the U.S. Department of Energy (DOE), and the National Household Travel Survey in 2009 (NHTS) [4, 24]. These studies include information regarding the percentage and type of vehicles in residential areas, the distances driven during a typical day, and arrival times to homes, among others. This information allows an approximation of the behavior of PEVs users, seen as an electric load varying over time. As an example, Fig 4.3 shows a probability distribution of EV start charging times from an EPRI report, presenting the likelihood that the drivers arrive at their homes and begin to charge their PEVs at each hour 25 .

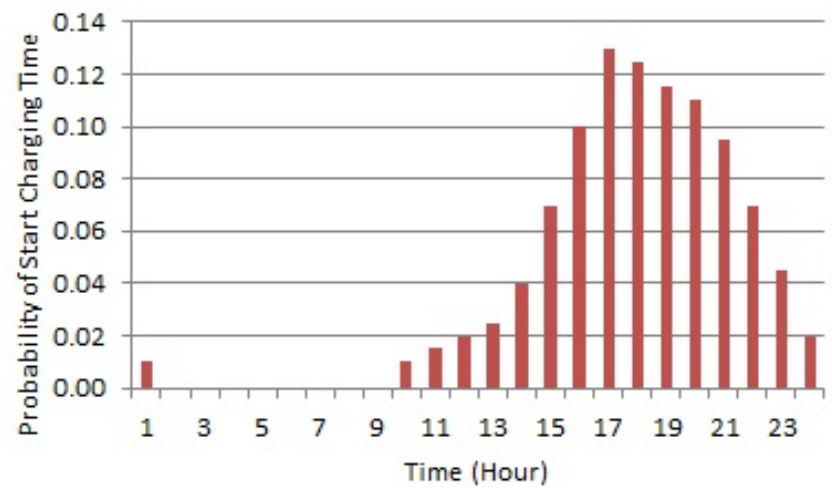

FIGURE 4.3: Probability distribution of start charging time (EPRI).

A roulette wheel selection concept is used in the simulation, representing the probability of start charging time as wedges in the wheel surface. The wedge $k$ of the stochastic model is calculated by

$$
W_{k}=\sum_{i=1}^{k} f_{i}
$$

where $f_{i}$ is the probability of the $i$ th start charging time. In each realization, a number between 0 and 1 is generated randomly. If the number is between $W_{i-1}$ and $W_{i}$, the 
$i$ th start charging time is selected. Hours with higher probability are more likely to be chosen. For the purpose of the simulation, an initial charging time is defined randomly every 24 hours starting at 9:00 a.m. for each vehicle, a time where the number of charging PEVs is expected to be zero.

\subsection{Initial State of Charge}

Parallel to the fact of determining the start charging time of PEVs, it is necessary to know the initial state of charge $(S O C)$ of their batteries. $S O C$ is defined as percentage of the charge remained in the battery. This information is obtained based on the same driving pattern studies presented in the previous section, since by knowing the distances traveled by vehicles, it is possible to estimate their energy consumption during the day. The NHTS 2009 study provides statistics related to this aspect, indicating the average daily driving distance by vehicles in the U.S. as shown in Fig 4.4 [24].

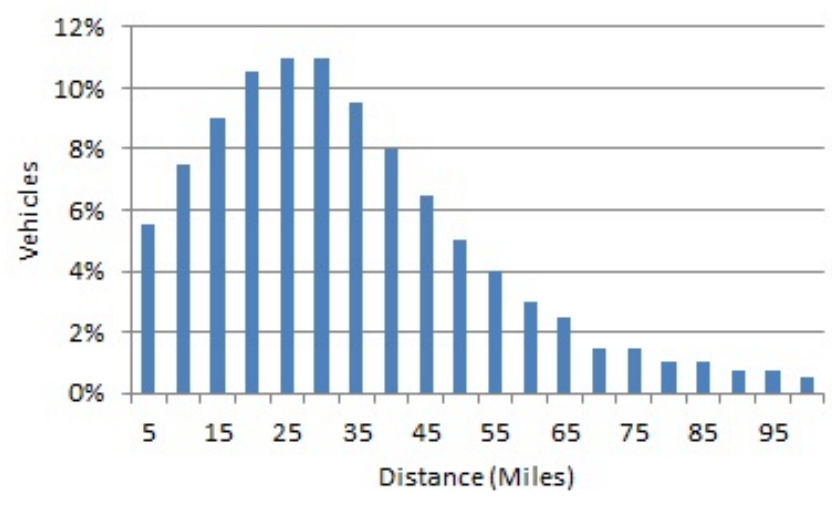

FiguRE 4.4: Average daily driving distance by vehicles (NHTS 2009).

The initial $S O C$ of these vehicles will directly depend on their $S O C$ when leaving the house, the distance traveled by each $\mathrm{PEV}, d$ in $\mathrm{km}$, the battery capacity, $b_{c}$ in $\mathrm{kWh}$, and their average fuel economy, $f_{e}$ in $\mathrm{kWh} / \mathrm{km}$. Accordingly, the $S O C$ of a PEV would be

$$
S O C=\left\{\begin{array}{cl}
1-\frac{f_{e} d}{b_{c}} & d<d_{\max } \\
S O C_{\min } & d \geq d_{\max }
\end{array}\right.
$$

where $d_{\max }$, in $\mathrm{km}$, corresponds to the maximum autonomy distance for each model of $\mathrm{PEV}$, and $S O C_{\min }$ represents the minimum $S O C$ allowed for operation because of life cycle considerations of the batteries. It is assumed that all vehicles are fully charged before departing each morning, so their $S O C$ when leaving equals to 1 . Moreover, the $S O C_{\min }$ for these PEVs is assumed to be 0.1 . 
Using the same roulette wheel selection concept described above, random numbers can be generated to determine the distance driven by PEVs each day. For the purpose of the simulation, these variables are also generated randomly every 24 hours starting at 9:00 a.m. for each vehicle.

\subsection{Charging Level}

As for charging levels, the Nissan Leaf has two charging receptacles, allowing Level 1 and 2 charging and high-voltage DC fast charging [22]. It is possible to connect Nissan Leaf to a 120 VAC standard household outlet, allowing a Level 1 charging power of 1.4 $\mathrm{kW}$. Models with on-board $3.3 \mathrm{~kW}$ and $6.6 \mathrm{~kW}$ Level 2 chargers can be fully recharged from empty in 8 and 4 hours, respectively, requiring a 220/240 VAC supply. Since Level 1 charging is meant for emergency cases, and DC fast charging requires a considerable infrastructure due to the amount of output power, these alternatives are not taken into account in this study on residential PDNs. Accordingly, it is assumed that half of the PEV users have a $3.3 \mathrm{~kW}$ on-board charger, and the rest own a $6.6 \mathrm{~kW}$ model installed in their vehicles. These chargers are modeled as constant real and reactive power loads, with $90 \%$ charging efficiency.

\subsection{PEV Penetration Level and Load Growth}

The penetration level of PEVs in the coming years has been numerously estimated by authors in order to depict their future impacts on the PDNs. For example, EPRI has proposed three penetration scenarios for the period between 2010 and 2030: low, medium and high, shown in Fig 4.5 [25]. This study will consider the high penetration scenario, modeling and evaluating the PEV connection for the next 5, 10 and 15 years, with penetration levels of $6 \%, 12 \%$ and $21 \%$, respectively.

Moreover, load growth is also considered as it affects the PDN simultaneously as PEVs penetrate the system. The DOE suggests using a mean incremental growth rate of $1.3 \%$ yearly for residential electricity consumption, due to new uses of electricity [26]. With this assumption, load growth for the next 5, 10 and 15 years, corresponds to $7 \%, 14 \%$ and $21 \%$ from now, respectively. It is possible to model the residential demand in the coming years accurately, by taking into account these two factors. 


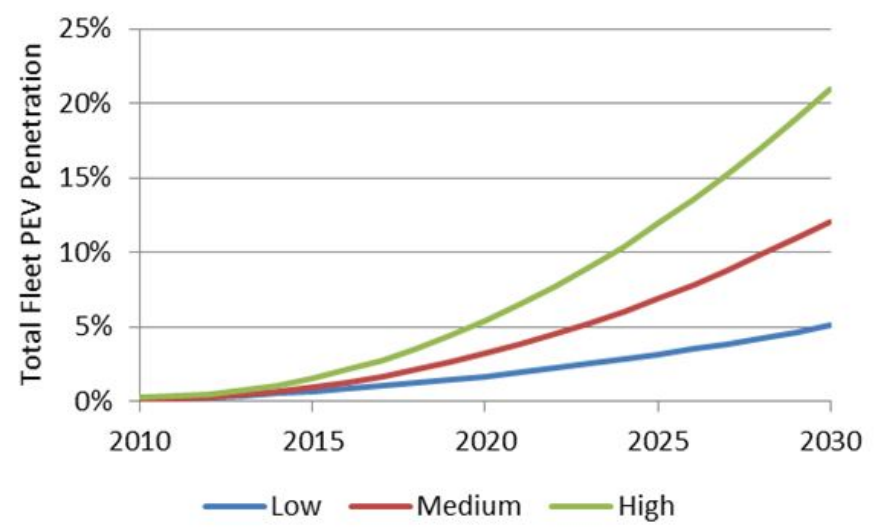

FIGURE 4.5: PEV penetration scenarios between 2010 and 2030 (EPRI).

\subsection{Number of Vehicles per House and PEV Distribution}

Finally, when considering a test case for the study and regarding the different penetration levels, it is necessary to make a proper estimate of the total number of vehicles and their location in the power system. If prior information about the distribution of residential users within the network is known, it is possible to make an approach of the quantity of PEVs in the PDN based on the above information, and taking into account the number and type of vehicles per household.

Then, it is necessary to determine the number of residential customers in a given PDN. As authors present in [27, it is possible to calculate the number of electricity customers $n_{E C i}$ connected to a feeder as

$$
n_{E C i}=\text { floor }\left(\frac{P D_{i}}{A V_{H L}}\right)
$$

where $P D_{i}$, in $\mathrm{kW}$, corresponds to the entire load at a bus on the feeder section and $A V_{H L}$, in $\mathrm{kW}$, is equal to the average hourly load of a residence; calculated as 2.0833 $\mathrm{kW}$.

After the number of electricity customers is defined, it is necessary to determine the number of vehicles per house, as the PEV penetration level depends on this variable. Data from the 2009 NHTS report show the percentage of houses with different number of vehicles in the U.S., as shown in Table 4.1 .

By performing a weighted average, the estimate equals to 2.12 vehicles per household. However, this number includes different types of vehicles such as vans, sports and trucks. 
TABLE 4.1: Percentage of houses with different number of vehicles.

\begin{tabular}{cc}
\hline $\begin{array}{c}\text { Number of vehicles } \\
\text { per household }\end{array}$ & $\begin{array}{c}\text { Percentage of houses } \\
\text { in 2009 NHTS Report }\end{array}$ \\
\hline Zero vehicle & $3.40 \%$ \\
One vehicle & $25.26 \%$ \\
Two vehicles & $42.61 \%$ \\
Three vehicles & $18.74 \%$ \\
Four vehicles & $6.57 \%$ \\
Five vehicles & $2.18 \%$ \\
>Five vehicles & $1.24 \%$ \\
\hline
\end{tabular}

TABle 4.2: Percentage of each type of vehicle in NHTS 2009.

\begin{tabular}{ccccc}
\hline Vehicle type & $\mathbf{1}$ & $\mathbf{2}$ & $\mathbf{3}$ & $\mathbf{4}$ \\
\hline Percentage & $51.48 \%$ & $10.35 \%$ & $23.00 \%$ & $15.17 \%$ \\
\hline
\end{tabular}

Hence, it is necessary to scale this number according to the percentage of vehicles including models such as the Nissan Leaf, i.e., Type 1 - compact sedan. Taking into account data in Table 4.2, the calculated number of PEVs per household nPEVi is given by

$$
n_{P E V i}=\text { floor }\left(1.09 x \cdot n_{E C i}\right)
$$

where $x$, in p.u., equals to the PEV penetration level and 1.09 corresponds to the product between the vehicles per household and the percentage of Type 1 cars. According to the above, the number of PEV connected to each bus in the IEEE 13 node test feeder is shown in Table 4.3 for a penetration level of $21 \%$ corresponding to the year 2030 . The $6 \%$ and $12 \%$ scenarios are computed similarly.

TABLE 4.3: Number of PEVs connected to each bus in IEEE 13 node test feeder with $21 \%$ penetration level.

\begin{tabular}{ccccc}
\hline Bus & Phase A & Phase B & Phase C & Total \\
\hline N_611 & 0 & 0 & 18 & 18 \\
N_634 & 17 & 13 & 13 & 43 \\
N_645 & 0 & 18 & 0 & 18 \\
N_646 & 0 & 25 & 0 & 25 \\
N_652 & 14 & 0 & 0 & 14 \\
N_670 & 2 & 7 & 13 & 22 \\
N_671 & 42 & 42 & 42 & 126 \\
N_675 & 53 & 7 & 32 & 92 \\
N_692 & 0 & 0 & 18 & 18 \\
Total & 128 & 112 & 136 & 376 \\
\hline
\end{tabular}




\section{Chapter 5}

\section{Coordinated Charging Schemes}

In order to mitigate impacts caused by the connection of PEVs in the PDN, coordinated charging schemes, that control how PEVs will recharge during a day, are proposed. The manner in which authors have approached coordinated charging schemes include resolving optimization functions (by minimizing the system losses or the elements loading), subject to the power flow equations in the system, and to successfully charge all vehicles connected to the grid in certain time. Additionally, implementation of dual tariffs is considered, in which consumers are encouraged to charge their PEVs at non-peak hours. However, this approach goes against market dynamics and its implementation tends to be complex. Finally, there are approaches from the corrective point of view, wherein the effect on electrical indicators are mitigated by network operators' decisions as certain preset system limits are exceeded, i.e., capacitors banks switching before undervoltage events.

Through coordinated charging schemes, it is also possible to perform a "delay" in the time when they start charging, guaranteeing that they are completely recharged before departing the next day. Thereby, the charging times for each car are reallocated, relieving problems such as overloading of elements (e.g. lines and transformers), and undervoltages at nodes. It is also possible to use these charging schemes in order to improve the PDN operation, i.e., performing peak load shaving.

In this regard, the implementation of two coordinated charging strategies based on [16] is proposed, in order to mitigate events of nodes undervoltage (Vi ; 0.95 p.u.) and elements overloading ( $\mathrm{Si} i \mathrm{Smax}$ ). In both cases, it is necessary to detect the moment when any of these two events occur. That is, each node and transformer is monitored hourly during the simulation so as to detect undervoltages and overloaded elements. If any of these situations happens, the possibility of delaying by one hour the charging of one or more PEVs connected to a given node, or connected at the downstream nodes of certain 
transformer, is evaluated. PEVs are then disconnected and added to a queue until they can start charging again without causing a new undervoltage or overload event. The order in which queued vehicles are reconnected to the PDN depends on their arrival time to their respective home, using a first-come, first-served policy. Similarly, the order in which charging vehicles are disconnected in case of an undervoltage or overload event depends on their arrival time so that latecomers are delayed first. According to the above, coordinated charging algorithms are shown in Fig 5.1 and Fig 5.2 , showing the undervoltage and overload mitigation, respectively.

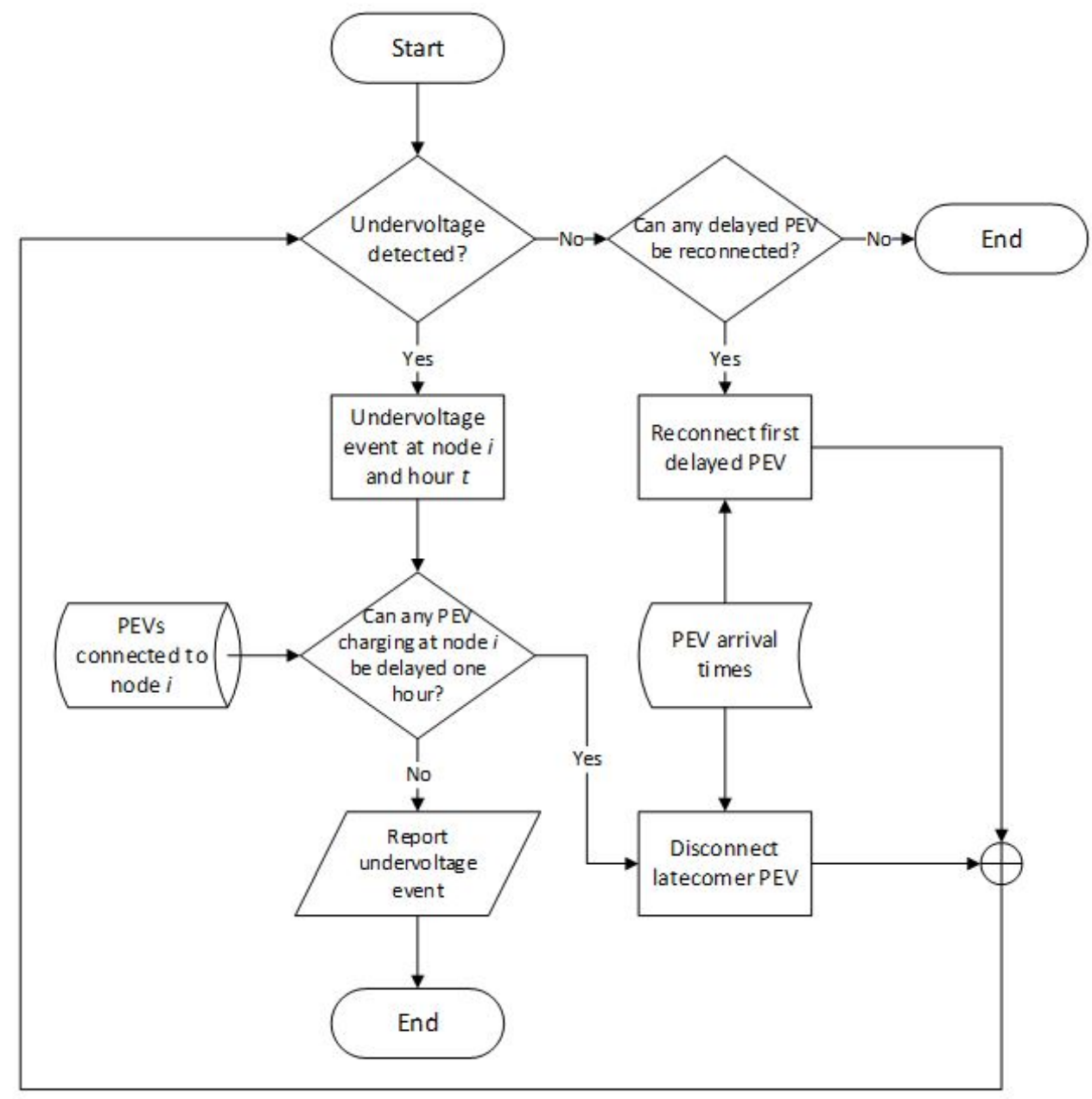

Figure 5.1: Coordinated charging scheme for undervoltage mitigation.

In principle, these coordinated charging schemes can be thought of as mitigation tools against adverse events in the system. However, it is possible to use these same concepts in order to improve the operation of the PDN by establishing operating limits of the system and, by controlling the charge of PEVs, meet certain objectives. For example, if the overloading mitigation scheme is implemented establishing a limit in the power delivered by the main network feeder, it is possible to perform a peak load shaving in the system by delaying the PEVs charging to a later non-peak hour. 


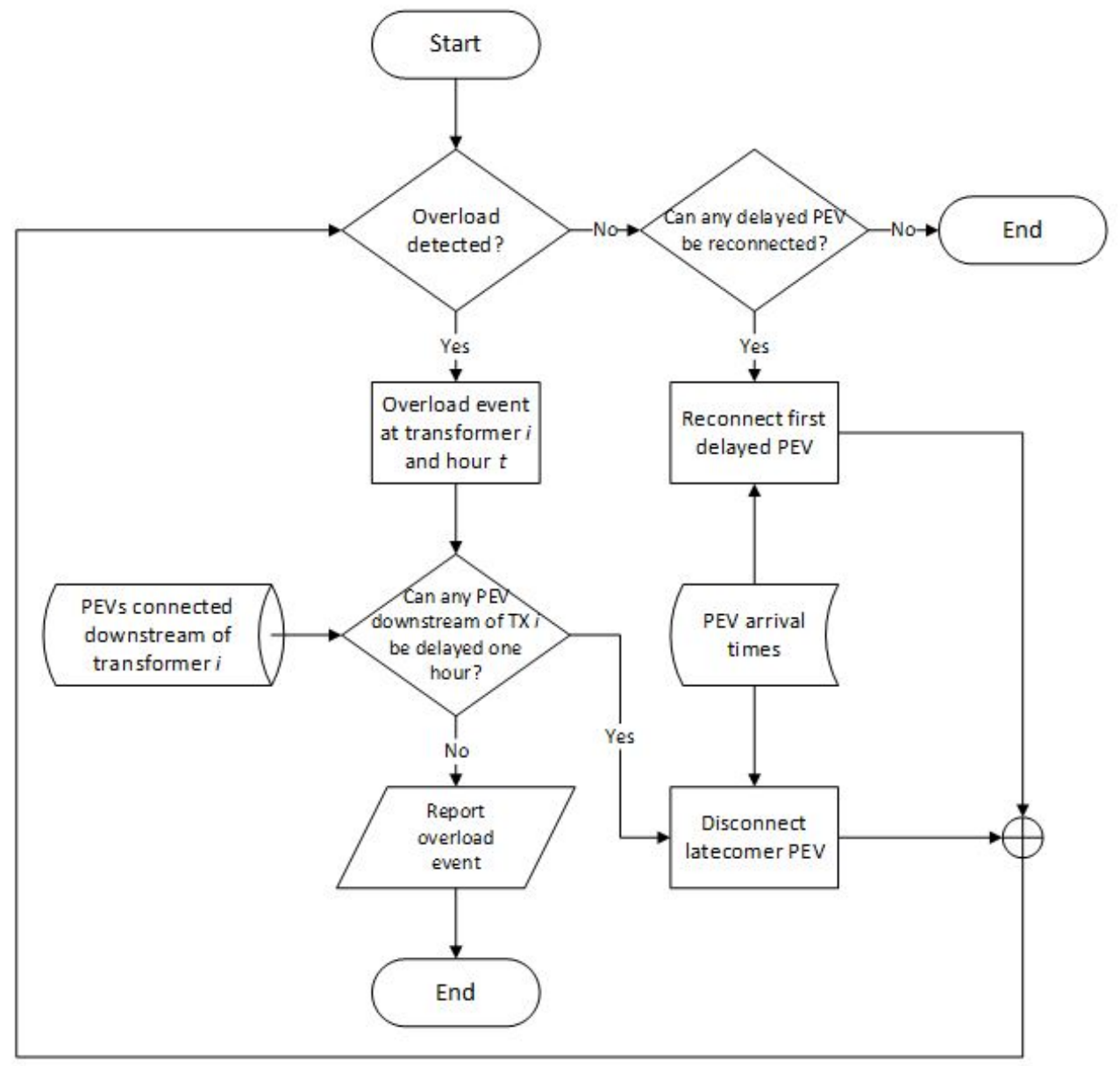

FIGURE 5.2: Coordinated charging scheme for overload mitigation. 


\section{Chapter 6}

\section{Simulation Parameters}

Once the plug-in electric charging model and coordinated charging schemes have been defined, it is necessary to establish additional simulation parameters taken into account by this study, as well as the computer tools used in order to obtain the results.

\subsection{System Description and Computer Tools}

As it has been previously mentioned, the IEEE 13 node test feeder is used in this paper. This network represents a residential radial network, containing eight spot loads in nodes $611,634,645,646,652,671,675$, and 692 . Additionally, bus 670 is the concentrated point load of the distributed load on line 632 to 671 , located at $1 / 3$ the distance from node 632 . There are two distribution voltage levels in this PDN: $4.16 \mathrm{kV}$ and $480 \mathrm{~V}$ (node 634), as well as a $115 \mathrm{kV}$ connection to a power transmission network.

The total number of electrical customers in the PDN is determined by (3) as 1643, and the number of PEVs by household, associated with a certain penetration level, is given by (4) and equals to 1.09x. In this regard, PEV distribution in the PDN was defined in Table III. Daily distance driven and starting charging times are determined as presented in Section III. The existing load profiles for the test system are modeled using three sets of 8760 points, representing three different hourly profiles for residential users during a year. Power factor values used for these households range between 0.75 and 0.93 , averaging 0.84 according to IEEE data. As it was previously mentioned, it is assumed that $3.3 \mathrm{~kW}$ and $6.6 \mathrm{~kW}$ on-board chargers are equally distributed among electrical customers, and the charging efficiency of the batteries is set at 90

Then, it is necessary to have a tool which allows modeling the PDN, including power flow analysis and PEV charging control and simulation. Keeping this in mind, EPRI's 
OpenDSS 28] is going to be used in order to develop the electrical model of the IEEE 13 node test feeder, to implement the needed modifications to add PEVs as indicated above, and to execute the power flows. The .DSS file corresponding to this test system was built according to IEEE's instructions. Furthermore, this work uses DSSim-PC software, a non-deterministic version of the DSSim-RT simulator, based in OpenDSS and used as a graphical interface for it [29. Successful results show the great advantage of this tool for Advanced Distribution Automation (ADA) activities such as fault location and isolation, feeder reconfiguration, service restoration and Volt-Var control [30]. Taking this into account, IEEE 13 node test feeder implemented in DSSim-PC, modified to include PEVs, is shown in Fig 6.1

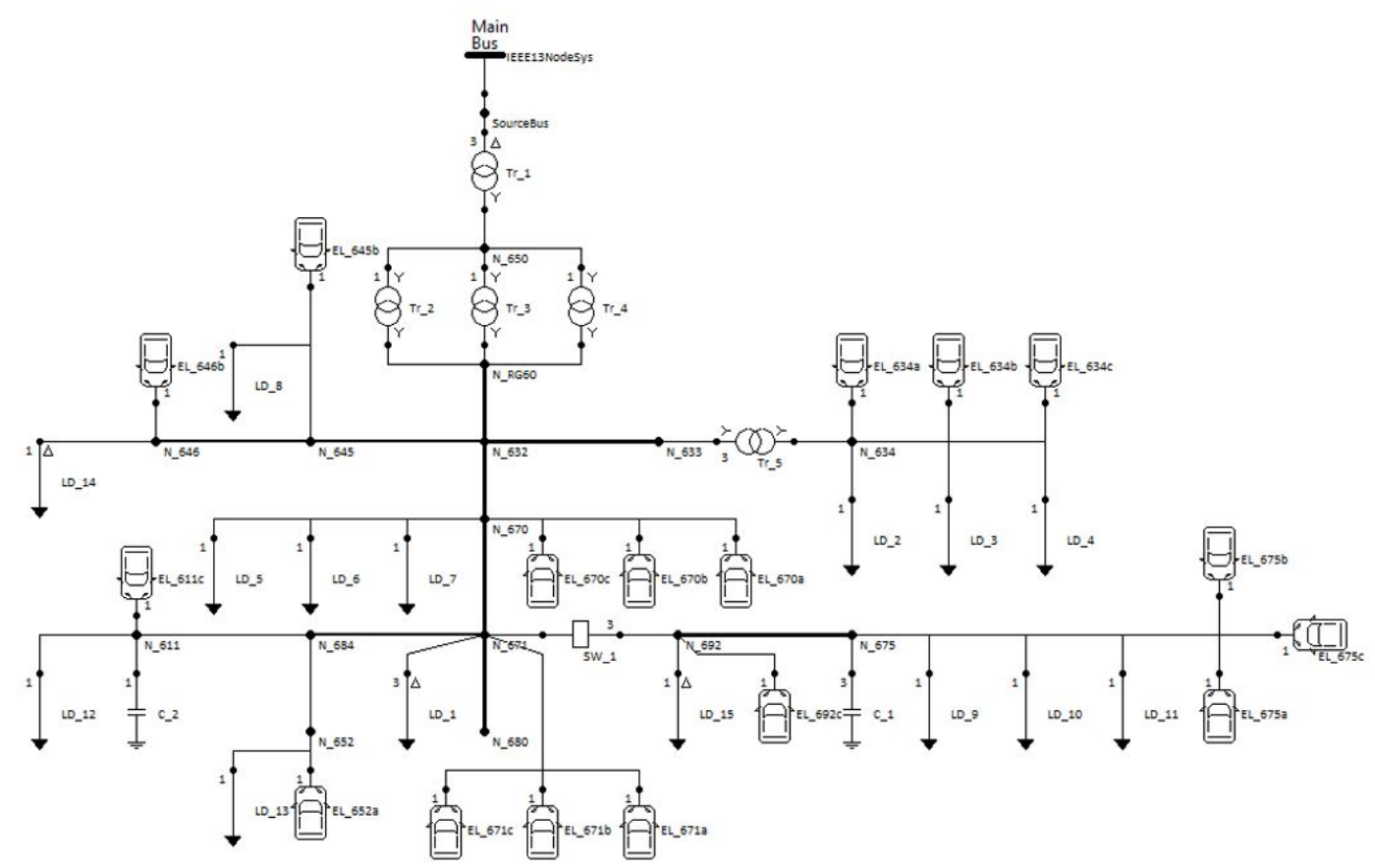

Figure 6.1: IEEE 13 node test feeder with PEVs implemented in DSSim-PC.

Additionally, this study uses a co-simulation between DSSim-PC and NI LabVIEW, performing the electrical simulations in the first, and the modeling, controlling and charging schemes in the second. In order to do so, it is possible to communicate these programs through TCP protocol. In this manner, LabVIEW's program consists in modeling the use of PEVs, acquiring DSSim-PC simulation results, performing coordinated charging schemes, and connecting/reconnecting the PEVs according to their arrivals or the decisions taken by the controller. Also, the designed PEV model is implemented in LabVIEW adding a user interface. Then, in terms of the proposal of a Distribution Management System, data including PEVs status, transformers loading, nodes voltages and overload or undervoltage events; is presented to the user through this interface. 


\subsection{Test Cases Definition}

The following test cases are defined for this study, according to the aspects presented above. Load profiles, voltage deviation, elements overloading, electrical losses, and voltage unbalance, are determined in every case.

- Year 2015: defined as the base case for the modeling and impact analysis, it is performed with the initial residential load profiles and 0\% PEV penetration.

- Year 2020: it is defined from the base case in this paper. A load growth of 7\% and a PEV penetration level of $6 \%$ are considered. This corresponds to 108 installed PEVs in the PDN, meaning $534.6 \mathrm{~kW}$ of additional power in the system, due to charging infrastructure.

- Year 2025: a load growth of $14 \%$ from 2015 and a PEV penetration level of $12 \%$ are defined. This equals to 212 installed PEVs in the PDN, and additional 1049.4 $\mathrm{kW}$ in the PEV power demand of the system.

- Year 2030: this study considers a load growth of $21 \%$ from 2015, as well as a 21\% PEV penetration level. This means a total of 376 installed PEVs in the PDN, meaning additional $1861.2 \mathrm{~kW}$ in the PEV power demand of the system. In this case, transformer XFM-1 and bus 675 are studied in terms of overload and undervoltage mitigation, respectively. 


\section{Chapter 7}

\section{Plug-in Electric Vehicles Model Implementation}

As it was previously defined, NI LabVIEW is used in order to perform the modeling, controlling and charging schemes of the PEVs. It is also possible to set up a user interface using this software, taking into account the information related to a PEV Management System, as well as the methodology correspondig to the model developed. In this regard, Fig.7.1 shows the Plug-in Electric Vehicles Model implemented in LabView.

The main screen allows a network operator or a user to observe different measurements in the electrical power system related to the use of PEVs, as well as taking control measures when it is necessary. First, a general topology of the PDN is shown including the location of the PEVs in the grid. It is also possible to verify certain PEVs variables such as if they are parked or not, their arrival hour, the distance traveled in a day and the corresponding initial SOC, the current SOC at any time and a boolean variable that indicates if the PEV is charging or not. These variables are also used internally in order to perform the simulation and take the corrective measures.

In terms of the PDN, it is possible to check the loading at the transformers and the minimum voltage at each node. These are variables of interest for a network operator, being the inputs of the coordinated charging schemes. In this regard, it is possible to select the control mode between None, Overload, Undervoltage or Overload and Undervoltage. A red light indicates when any of these violations occurs. Finally, there is a Run and Stop button for the simulation, whose times are controlled in DSSim-PC, as well as an indicator for the simulation time.

Finally, programming related to the PEV model and the coordinated charging schemes is also made in NI LabVIEW. In this regard, Fig 7.2 shows the block diagram of the 


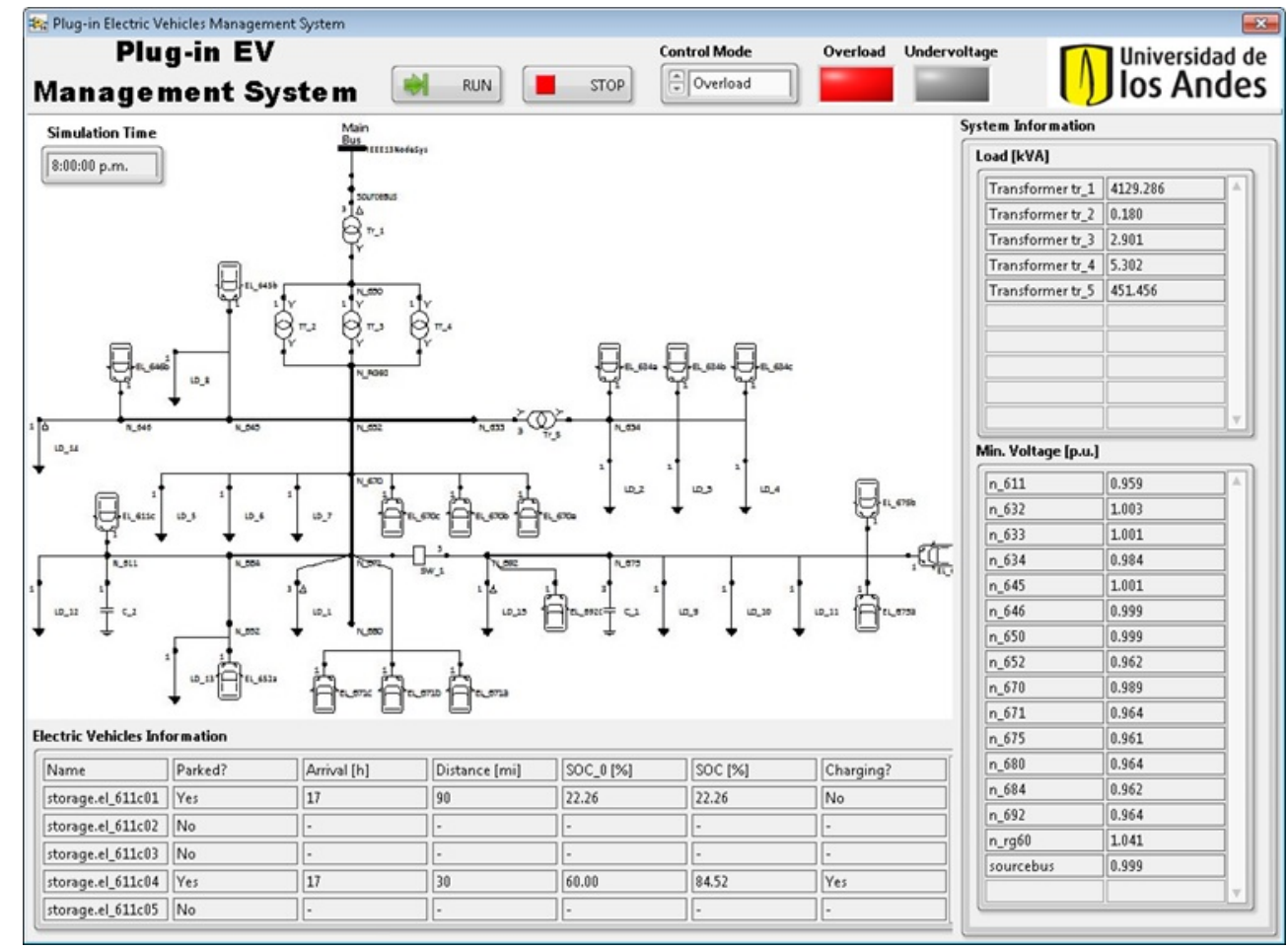

Figure 7.1: PEV Management System implemented in LabView.

implementation, showing a Producer-Consumer architecture in which the first structure acquires and writes data to the electrical system in DSSim-PC, while the second performs the PEV simulation and the coordinated charging operations. More details regarding the implementation are shown in the Appendix 1.

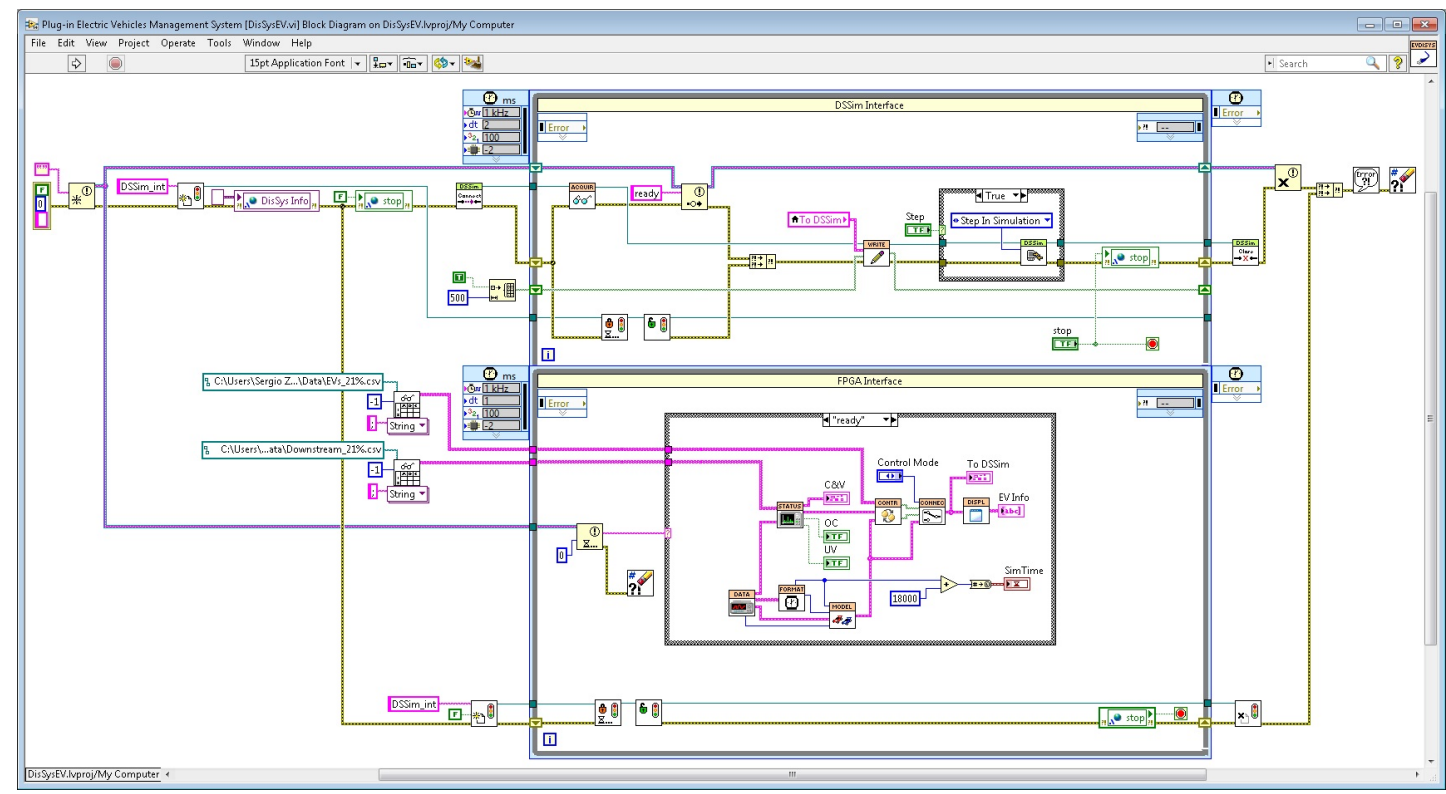

Figure 7.2: PEV Management System schematic implementation in LabView. 


\section{Chapter 8}

\section{Results}

As the simulation parameters and test cases have been defined, results obtained from the $\mathrm{PEV}$ model are presented below, corresponding to each of the metrics defined in order to assess the impacts of PEV connection, as well as the mitigation strategies proposed by the coordinated charging schemes.

\subsection{Feeder Load}

Given the yearly load growth and the connection of new loads associated with a charging infrastructure required for PEV operation, daily power demand in the distribution feeder is expected to considerably increase. In this regard, daily average feeder demand curves in the four test cases are depicted in Fig, 8.1 and detailed statistics are shown in Table 8.1. The effect of load growth can be observed as the curves offset when compared to 2015. As it was expected, there is an increase in demand between the hours in which users arrive to their households and plug their PEVs. Furthermore, it is possible to check how the yearly peak load increases steadily up to $42.65 \%$ from 2015 to 2030 . Average daily peak load and average daily load also increase by a similar percentage, $42.99 \%$ and $31.03 \%$, respectively. Finally, there is a decrease in average daily load factor for the system from 0.857 to 0.776 during these years, as a result of a higher increase of peak load with respect to average load in the PDN.

\subsection{Voltage Deviation}

As a consequence of connecting new loads corresponding to PEVs, there may be a drop in voltage profiles of some residential nodes, incurring in a violation of the minimum 


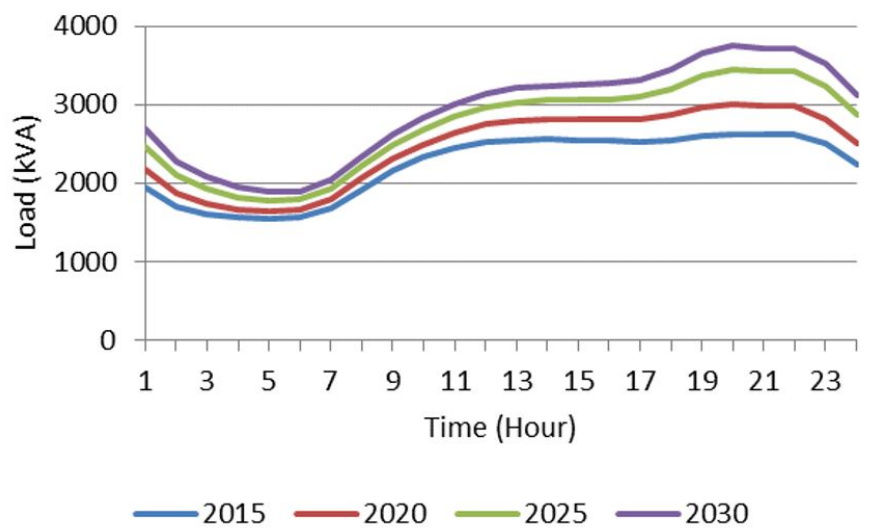

FIGURE 8.1: PDN average daily feeder demand curve for each test case.

TABLE 8.1: Feeder load data comparison.

\begin{tabular}{lcccc}
\hline Year & $\begin{array}{c}\text { Yearly Peak } \\
\text { Load } \\
(\mathbf{k V A})\end{array}$ & $\begin{array}{c}\text { Average Daily } \\
\text { Peak Load } \\
\text { (kVA) }\end{array}$ & $\begin{array}{c}\text { Average } \\
\text { Daily Load } \\
\text { (kVA) }\end{array}$ & $\begin{array}{c}\text { Average } \\
\text { Daily Load } \\
\text { Factor }\end{array}$ \\
\hline $\mathbf{2 0 1 5}$ & 3281.8 & 2628.9 & 2225.2 & 0.857 \\
$\mathbf{2 0 2 0}$ & 3773.6 & 3010.2 & 2456.5 & 0.816 \\
$\mathbf{2 0 2 5}$ & 4214.1 & 3444.8 & 2719.6 & 0.789 \\
$\mathbf{2 0 3 0}$ & 4681.6 & 3759.1 & 2915.8 & 0.776 \\
\hline
\end{tabular}

allowable limits for system operation (0.95 p.u.). Therefore, voltage deviation in the nodes of the PDN is studied, in order to determine the occurrence of these violations and, if it is necessary, implement measures of mitigation, i.e., coordinated charging schemes.

In this regard, special attention is given to bus 675 , as it has the lowest voltage profile in the test system. The average daily voltage profile for this bus is depicted in Fig 8.2 , The effect of load growth and PEV connection can be seen again, as the curve offsets to lower levels, and a considerable drop between 17:00 and 23:00 appears. It is possible to define the average voltage deviation $V_{d}$ for a node as

$$
V_{d}=\frac{\sum_{i=1}^{N}\left|V_{i}-1\right|}{N}
$$

where $V_{i}$, in p.u., corresponds to the node voltage measured, $N$ equals to the number of measures, and the reference voltage is $1.0 \mathrm{p} . \mathrm{u}$. According to this, average voltage deviations in bus 675 for each case correspond to $1.96 \%, 2.12 \%, 2.30 \%$, and $2.47 \%$, respectively. It is also possible to verify the appearance of undervoltage events in year 2030, in cases corresponding to the highest PDN demand. 


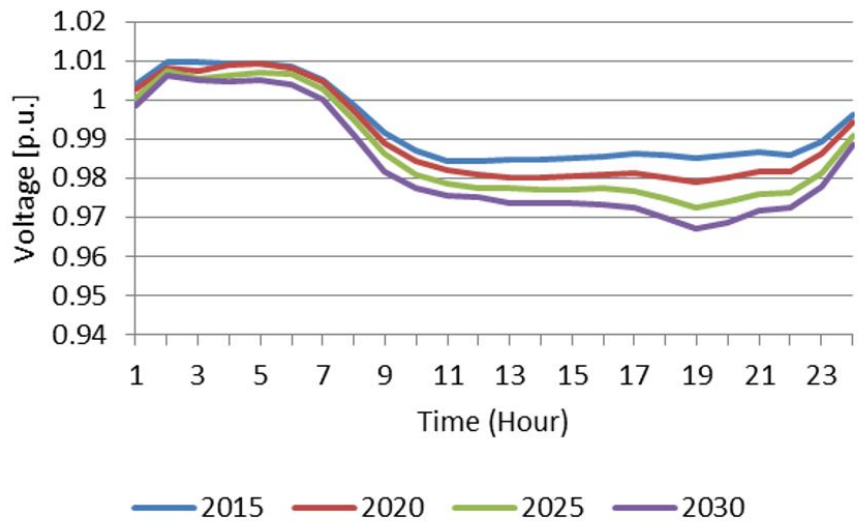

Figure 8.2: Bus 675 average daily voltage profile for each test case.

Therefore, it is possible to verify the coordinated charging scheme by setting it to undervoltage control, as it is shown in Fig.8.3. Firstly, a typical voltage profile in 2015 is depicted, showing a normal operation inside the limits (blue). By 2030, voltage profile starts to drop significantly around peak load hours, even beyond $0.95 \mathrm{p} . \mathrm{u}$ (red). When implementing the charging scheme, it is possible to mitigate these undervoltage events by delaying the PEV charging, ensuring in this manner that the node is not operating below its limit, as the effect in voltage profile is seen a few hours later (green).

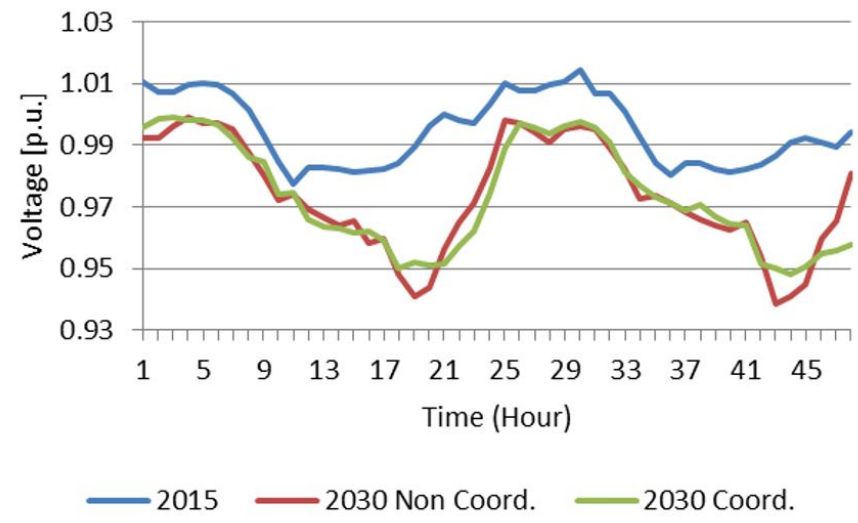

Figure 8.3: Bus 675 typical voltage profile during two days in a) 2015, b) 2030 noncoordinated charging, and c) 2030 coordinated charging.

\subsection{Elements Overloading and Peak Shaving}

One of the most common problems relates to the overload of elements in the PDN, specifically transformers associated with residential areas, affecting their lifetime. In this way, transformer XFM-1 is analyzed next and its average daily profile is shown in Fig 8.4. Similarly to the previous studied metrics, there is a steady increase in its load, especially around peak hours. Detailed statistics about the transformer during 
the four test cases are shown in Table 8.2. Peak load increases up to $30.3 \%$ in 2030, while average daily peak load and average daily load increase by $35.64 \%$ and $28.79 \%$, respectively. Finally, the average daily load factor also decreases over time.

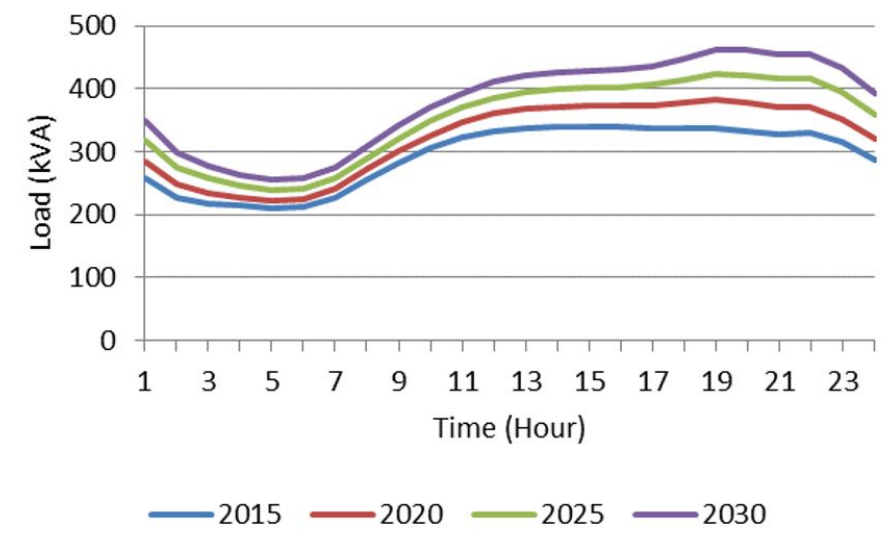

FiguRE 8.4: Transformer XFM-1 average daily load profile for each test case.

TABLE 8.2: Transformer XFM-1 loading data comparison.

\begin{tabular}{lcccc}
\hline Year & $\begin{array}{c}\text { Yearly Peak } \\
\text { Load } \\
\text { (kVA) }\end{array}$ & $\begin{array}{c}\text { Average Daily } \\
\text { Peak Load } \\
\text { (kVA) }\end{array}$ & $\begin{array}{c}\text { Average } \\
\text { Daily Load } \\
\text { (kVA) }\end{array}$ & $\begin{array}{c}\text { Average } \\
\text { Daily Load } \\
\text { Factor }\end{array}$ \\
\hline $\mathbf{2 0 1 5}$ & 442.0 & 340.6 & 292.8 & 0.860 \\
$\mathbf{2 0 2 0}$ & 506.1 & 382.2 & 320.9 & 0.840 \\
$\mathbf{2 0 2 5}$ & 534.8 & 423.0 & 349.7 & 0.827 \\
$\mathbf{2 0 3 0}$ & 576.0 & 462.0 & 377.1 & 0.816 \\
\hline
\end{tabular}

Given that since 2020 the yearly peak load is greater than the transformer rating (500 $\mathrm{kVA}$ ) overload 'events are occurring from that year. Specifically, the percentage of times in which this happen are $0.01 \%, 0.53 \%$ and $4.90 \%$ in 2020, 2025 and 2030, respectively. Then, a viable option in order to mitigate these events, as they become more frequent with the years, is to implement the coordinated charging scheme proposed. In this regard, Fig 8.5 represents the operation of the overloading control for transformer XFM1 in two typical days. Firstly, a typical load profile in 2015 is depicted, showing normal operation below the maximum rating (blue). By 2030, this curve rises significantly around peak load hours, even beyond $500 \mathrm{kVA}$ (red). Again, by implementing the charging scheme, it is possible to mitigate these overload events by delaying the PEV charging, ensuring in this manner that the transformer is not operating above its rating, as the effect in its loading is seen a few hours later (green). In this scenario, a limit of $425 \mathrm{kVA}$ was defined in the coordinated charging scheme. Even if the transformer rating equals to $500 \mathrm{kVA}$, by adjusting this parameter it is possible to perform a peak shaving in the load curve. This means than rather than acting as a mitigation tool, coordinated charging can also improve the system operation. 


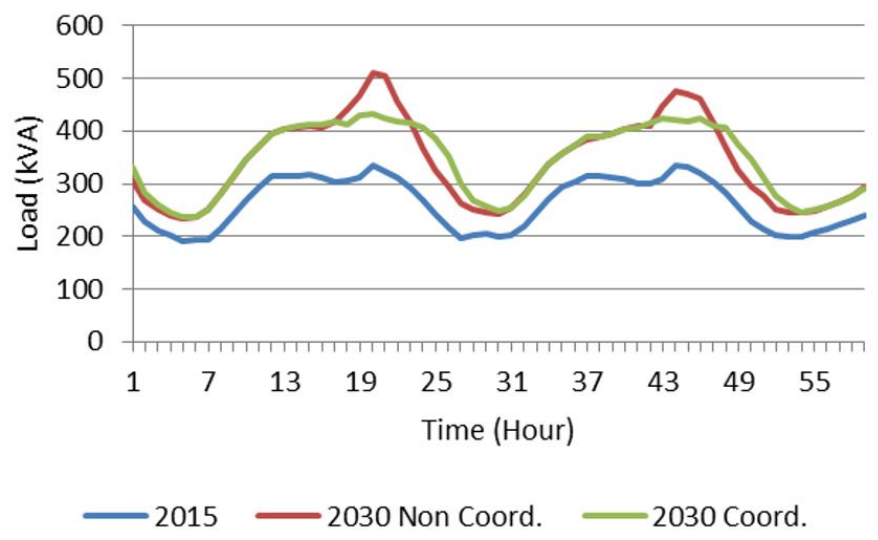

FIgURE 8.5: Transformer XFM-1 typical load profile during two days in a) 2015, b) 2030 non-coordinated charging, and c) 2030 coordinated charging.

This can be further seen by analyzing the load factors for these curves, corresponding to 0.775 (2015), 0.674 (2030-NC), and 0.795 (2030-C). Hence, implementation of coordinated charging may yield to a higher load factor, using PEVs as an opportunity to improve the system's performance.

\subsection{Electrical Losses}

By performing an analysis of the load profile in the PDN, there is enough data to determine, similarly, the impact of electrical losses in the system. These results are depicted in Fig.8.6, showing how the losses increase proportionally with the system load. On average, electrical losses equal to $2.79 \%$ of the total PDN load.

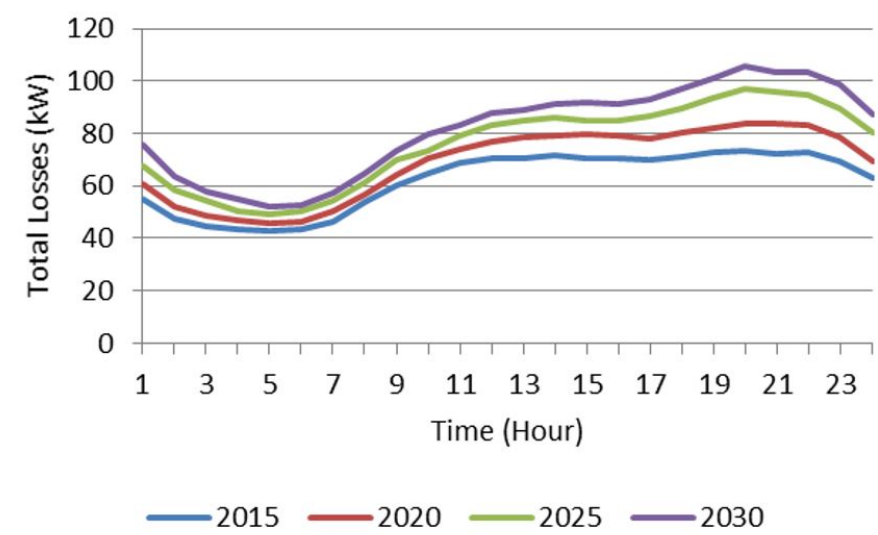

Figure 8.6: Average daily electrical losses for each test case. 


\subsection{Voltage Unbalance}

Finally, when distributing PEVs throughout the PDN, voltage unbalance effects may occur due to the connection of single phase chargers to different feeders. In this regard, using per unit quantities, voltage unbalance at time $i$ is given by

$$
V_{U B i}=\frac{\max \left(\left|V_{1 i}-V_{A V G}\right|,\left|V_{2 i}-V_{A V G}\right|,\left|V_{3 i}-V_{A V G}\right|\right)}{V_{A V G}}
$$

where the maximum deviation from the average line voltage is referred to the average of the three voltages, $V_{A V G}$ [31]. As a result of this analysis for bus 650, average voltage unbalances are shown in Table 8.3 for the test cases studied. Voltage unbalance increases with the years, due to the connection of new single phase chargers along the system. It is up to each network operator to determine if this increase in voltage unbalance should be addressed by performing correction measures in the PDNs.

TABLE 8.3: Average voltage unbalance at Bus 650.

\begin{tabular}{ccccc}
\hline Year & $\mathbf{2 0 1 5}$ & $\mathbf{2 0 2 0}$ & $\mathbf{2 0 2 5}$ & $\mathbf{2 0 3 0}$ \\
\hline Voltage Unbalance & $2.74 \%$ & $2.99 \%$ & $3.32 \%$ & $3.61 \%$ \\
\hline
\end{tabular}




\section{Chapter 9}

\section{Conclusions}

Due to the connection of PEVs in the coming years, there will certainly be impacts in the PDNs that must be addressed. In order to do it, several factors should be taken into account such as PEVs characteristics, driving patterns and current grid status. In this regard, as models get more refined and accurate, including deterministic and stochastic data, the results obtained will have a much better quality and will help the network operators to adequately perform the planning and maintenance of their power systems.

The results of the PEV impacts study show that peak load and, subsequently, elements overloading are the more concerning issues for the PDN as PEV penetration increases. Hence, the design and implementation of mitigation strategies, such as coordinated charging schemes, allow network operators to address these issues, by implementing a Distribution Management System that provides enough information about the PDN in order to take corrective measures. 


\section{Bibliography}

[1] Robert C Green, Lingfeng Wang, and Mansoor Alam. The impact of plug-in hybrid electric vehicles on distribution networks: A review and outlook. Renewable and Sustainable Energy Reviews, 15(1):544-553, 2011.

[2] Mark Duvall, Eladio Knipping, M Alexander, L Tonachel, and C Clark. Environmental assessment of plug-in hybrid electric vehicles. EPRI, July, 2007.

[3] P Denholm and W Short. An evaluation of utility system impacts and benefits of optimally dispatched. National Renewable Energy Laboratory, Tech. Rep. NREL/TP-620-40293, 2006.

[4] Soroush Shafiee, Mahmud Fotuhi-Firuzabad, and Mohammad Rastegar. Investigating the impacts of plug-in hybrid electric vehicles on power distribution systems. Smart Grid, IEEE Transactions on, 4(3):1351-1360, 2013.

[5] Ryan Liu, Luther Dow, and Edwin Liu. A survey of PEV impacts on electric utilities. In Innovative Smart Grid Technologies (ISGT), 2011 IEEE PES, pages 1-8. IEEE, 2011.

[6] Farhad Shahnia, Arindam Ghosh, Gerard Ledwich, and Firuz Zare. Predicting voltage unbalance impacts of plug-in electric vehicles penetration in residential low-voltage distribution networks. Electric Power Components and Systems, 41 (16):1594-1616, 2013.

[7] Jason M Sexauer, Kerry D McBee, and Kelly A Bloch. Applications of probability model to analyze the effects of electric vehicle chargers on distribution transformers. Power Systems, IEEE Transactions on, 28(2):847-854, 2013.

[8] GA Putrus, Pasist Suwanapingkarl, David Johnston, EC Bentley, and Mahinsasa Narayana. Impact of electric vehicles on power distribution networks. In Vehicle Power and Propulsion Conference, 2009. VPPC'09. IEEE, pages 827-831. IEEE, 2009. 
[9] Jason Taylor, Arindam Maitra, Mark Alexander, Daniel Brooks, and Mark Duvall. Evaluations of plug-in electric vehicle distribution system impacts. In Power and Energy Society General Meeting, 2010 IEEE, pages 1-6. IEEE, 2010.

[10] Abdulelah Yousef Alharbi. Impact of plug in electric vehicle battery charging on a distribution system based on real-time digital simulator. 2013.

[11] Mostafa F Shaaban, Yasser M Atwa, and Ehab F El-Saadany. PEVs modeling and impacts mitigation in distribution networks. Power Systems, IEEE Transactions on, 28(2):1122-1131, 2013.

[12] Luis Pieltain Fernández, TGS Roman, Rafael Cossent, C Mateo Domingo, and Pablo Frias. Assessment of the impact of plug-in electric vehicles on distribution networks. Power Systems, IEEE Transactions on, 26(1):206-213, 2011.

[13] Peter Richardson, Damian Flynn, and Andrew Keane. Impact assessment of varying penetrations of electric vehicles on low voltage distribution systems. In 2010 IEEE Power and Energy Society General Meeting [proceedings]. IEEE, 2010.

[14] Luther Dow, Mike Marshall, Le Xu, J Romero Aguero, and H Lee Willis. A novel approach for evaluating the impact of electric vehicles on the power distribution system. In Power and Energy Society General Meeting, 2010 IEEE, pages 1-6. IEEE, 2010.

[15] Franz H Pereyra Zamora, Henrique Kagan, Marcelo A Pelegrini, LG Gardiman, L Zamboni, M Gavazzi, MAP Fredes, CAM Gonçalves, and JP Niggli Silva. Evaluation of the impact of electric vehicles on distribution systems combining deterministic and probabilistic approaches. 2013.

[16] Rong-Ceng Leou, Chun-Lien Su, and Chan-Nan Lu. Stochastic analyses of electric vehicle charging impacts on distribution network. Power Systems, IEEE Transactions on, 29(3):1055-1063, 2014.

[17] Jayakrishnan Radhakrishna Pillai and Birgitte Bak-Jensen. Impacts of electric vehicle loads on power distribution systems. In Vehicle Power and Propulsion Conference (VPPC), 2010 IEEE, pages 1-6. IEEE, 2010.

[18] Kristien Clement-Nyns, Edwin Haesen, and Johan Driesen. The impact of charging plug-in hybrid electric vehicles on a residential distribution grid. Power Systems, IEEE Transactions on, 25(1):371-380, 2010.

[19] Ganesh K Venayagamoorthy, Pinaki Mitra, Keith Corzine, and C Huston. Real-time modeling of distributed plug-in vehicles for V2G transactions. In 
Energy Conversion Congress and Exposition, 2009. ECCE 2009. IEEE, pages 3937-3941. IEEE, 2009.

[20] Sara Deilami, Amir S Masoum, Paul S Moses, and Mohammad AS Masoum. Real-time coordination of plug-in electric vehicle charging in smart grids to minimize power losses and improve voltage profile. Smart Grid, IEEE Transactions on, 2(3):456-467, 2011.

[21] William H Kersting. Radial distribution test feeders. In Power Engineering Society Winter Meeting, 2001. IEEE, volume 2, pages 908-912. IEEE, 2001.

[22] 2015 Nissan Leaf. http://www.nissanusa.com/electric-cars/leaf/. Accessed: 2015-05-31.

[23] Jay Cole. Nissan Leaf sales strengthen in March, takes all-time US plug-in sales lead. http://insideevs.com/ nissan-leaf-sales-strengthen-in-march-takes-overall-us-plug-in-sales-lead/. Accessed: 2015-05-31.

[24] U.S. Department of Transportation. 2009 National Household Travel Survey. http://nh-ts.ornl.gov, Accessed: 2015-05-31.

[25] M Duvall, M Alexander, A Maitra, D Saucedo, B Jungers, J Halliwell, R Entriken, M Davis, and K Davis. Transportation electrification-a technology overview, 2011.

[26] U.S. Department of Energy. Annual energy outlook, with projections to 2030. U.S. Energy Information Administration, 2007.

[27] Isha Sharma, Claudio A Cañizares, and Kankar Bhattacharya. Modeling and impacts of smart charging pevs in residential distribution systems. In Power and Energy Society General Meeting, 2012 IEEE, pages 1-8. IEEE, 2012.

[28] Electric Power Research Institute. OpenDSS. http://sourceforge.net/projects/electricdss/. Accessed: 2015-05-31.

[29] D. Montenegro. DSSim-PC. http://sourceforge.net/projects/dssimpc/. Accessed: 2015-05-31.

[30] D Montenegro, M Hernandez, and GA Ramos. Real time OpenDSS framework for distribution systems simulation and analysis. In Transmission and Distribution: Latin America Conference and Exposition (TED-LA), 2012 Sixth IEEE/PES, pages 1-5. IEEE, 2012.

[31] P Pillay and M Manyage. Definitions of voltage unbalance. IEEE Power Engineering Review, 21(5):50-51, 2001. 


\section{Appendices}

Next, the Sub-VIs used in the final implementation are shown below. These correspond to the intermediate steps required for the program to execute.

- Acquire VI

Sub-VI responsible for acquire the electrical data from the simulation in DSSimPC.

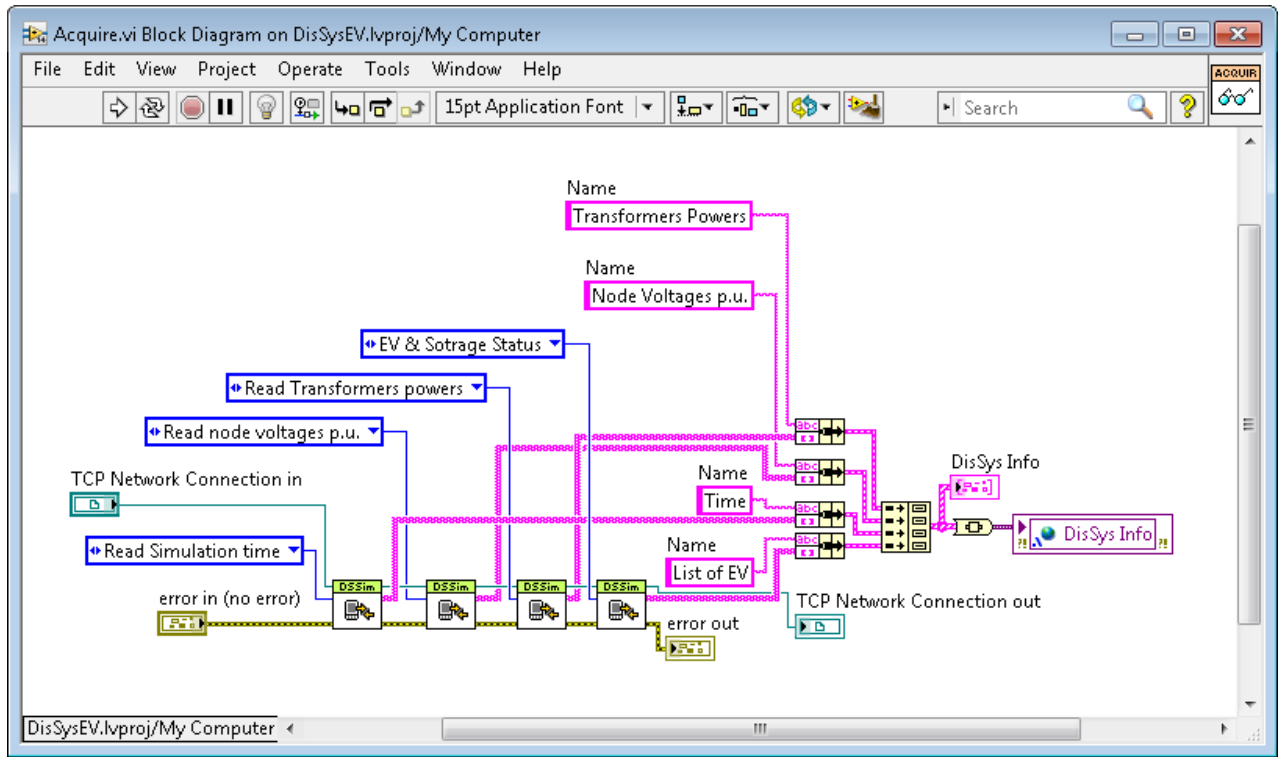

Figure 1: Acquire VI

- Calculation VI

Sub-VI responsible for determining the variables of each PEV such as initial SOC and required charging time based on the travelled distance and arrival time.

- Connect VI

Sub-VI responsible for determining when a PEV should be connected to the PDN or not, according to the selected charging scheme. 


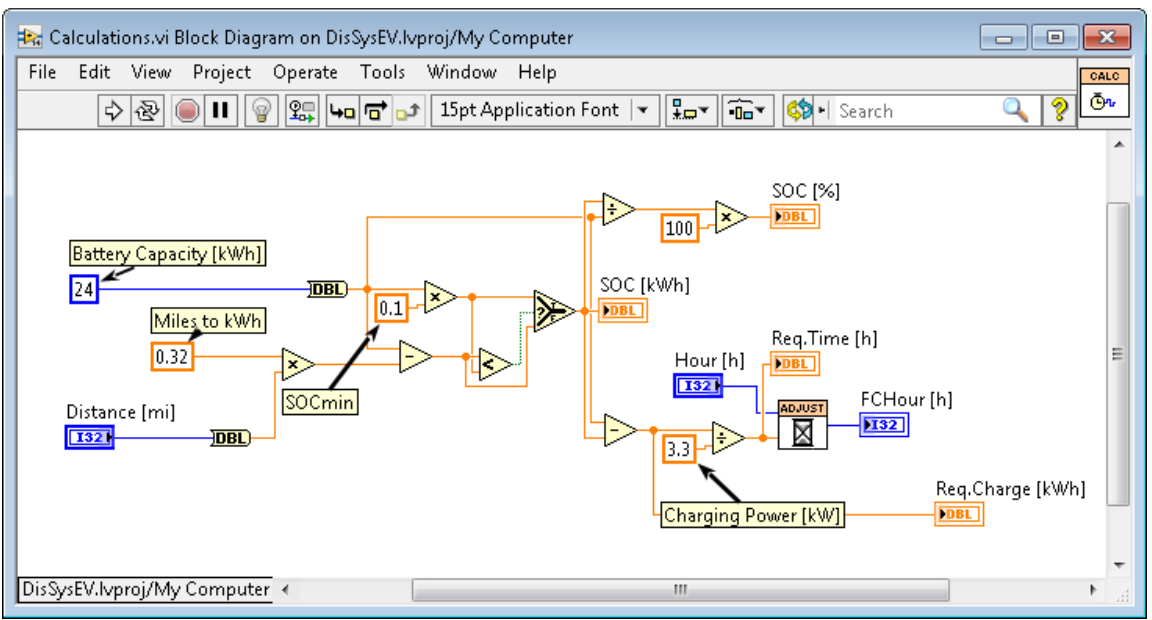

FIGURE 2: Calculation VI

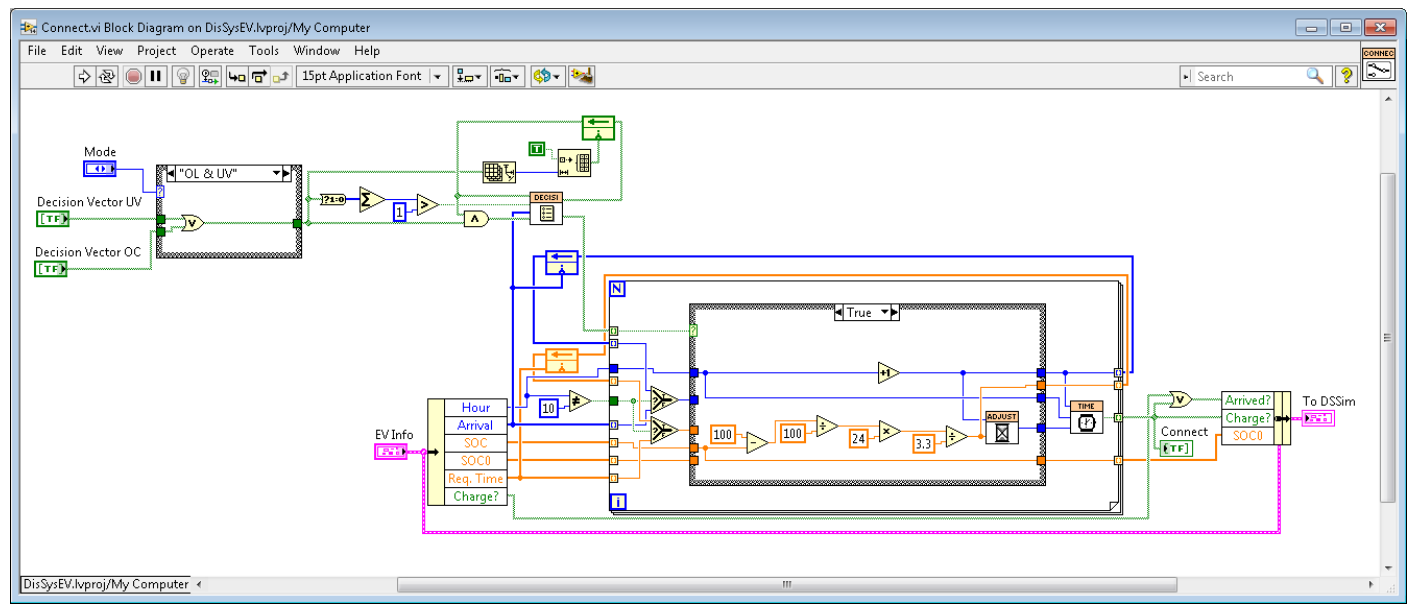

Figure 3: Connect VI

- Controller VI

Sub-VI responsible for generating a decision vector that is subsequently used for determining when a PEV should be connected to the PDN or not.

- Data VI

Sub-VI responsible for reading the information acquired from the electrical simulation in DSSim-PC.

- Decision VI

Sub-VI responsible for deciding if it is possible to disconnect one or more PEVs at a certain node/transformer when a violation occurs.

- Display VI

Sub-VI responsible for showing the program information in the user interface, including the measurement variables and the controller actions. 


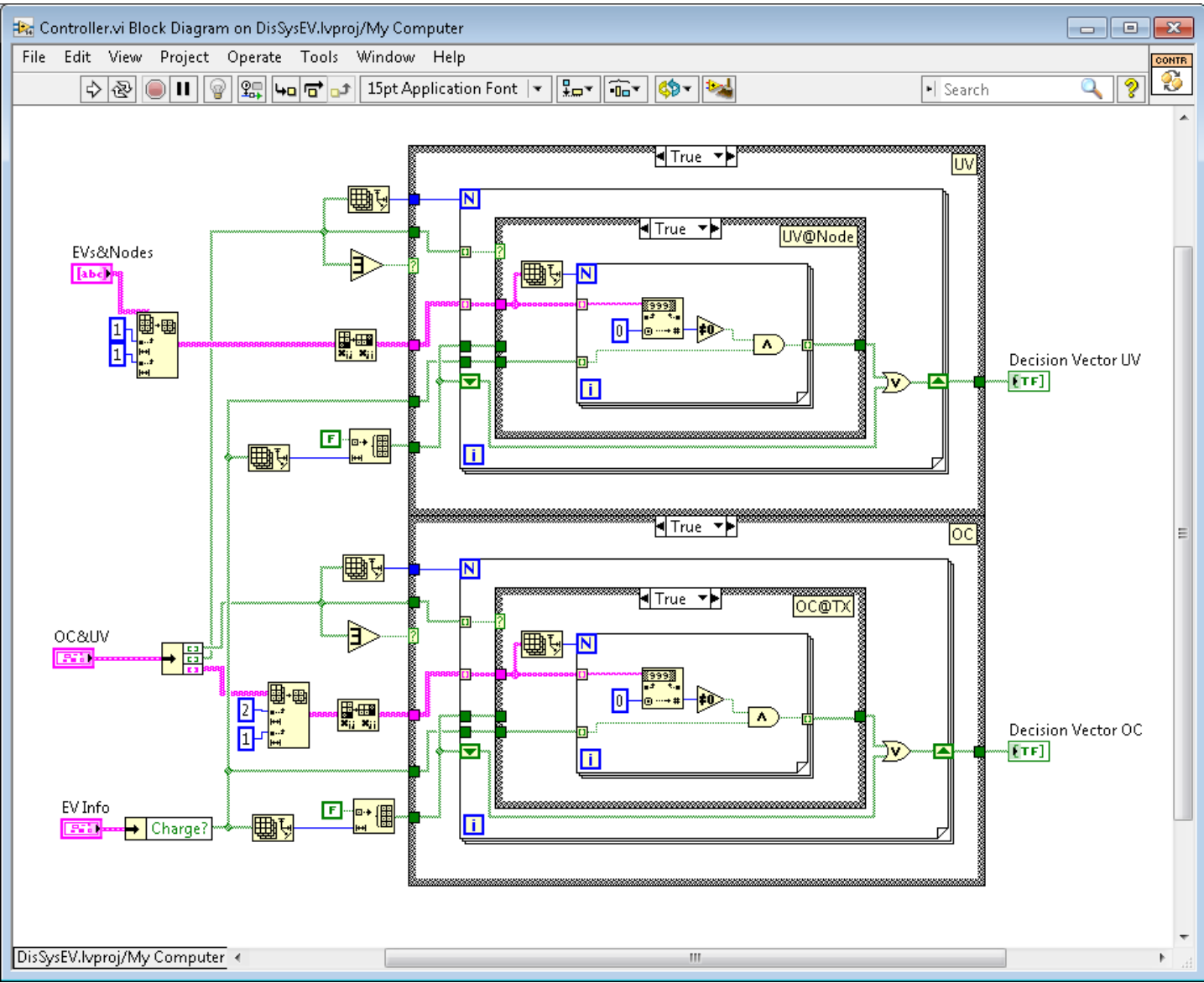

Figure 4: Controller VI

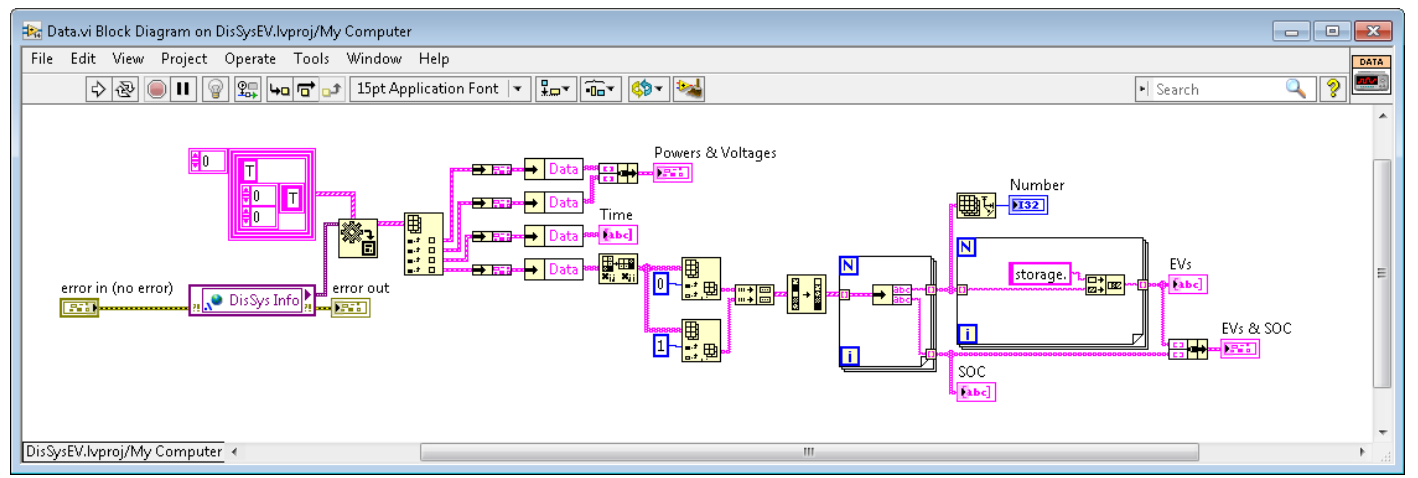

Figure 5: Data VI

- EV Arrival VI

Sub-VI responsible for generating randomly distributed arrival times for the PEVs according with the distribution proposed.

- EV Distance VI

Sub-VI responsible for generating randomly distributed travel distances for the PEVs according with the distribution proposed. 


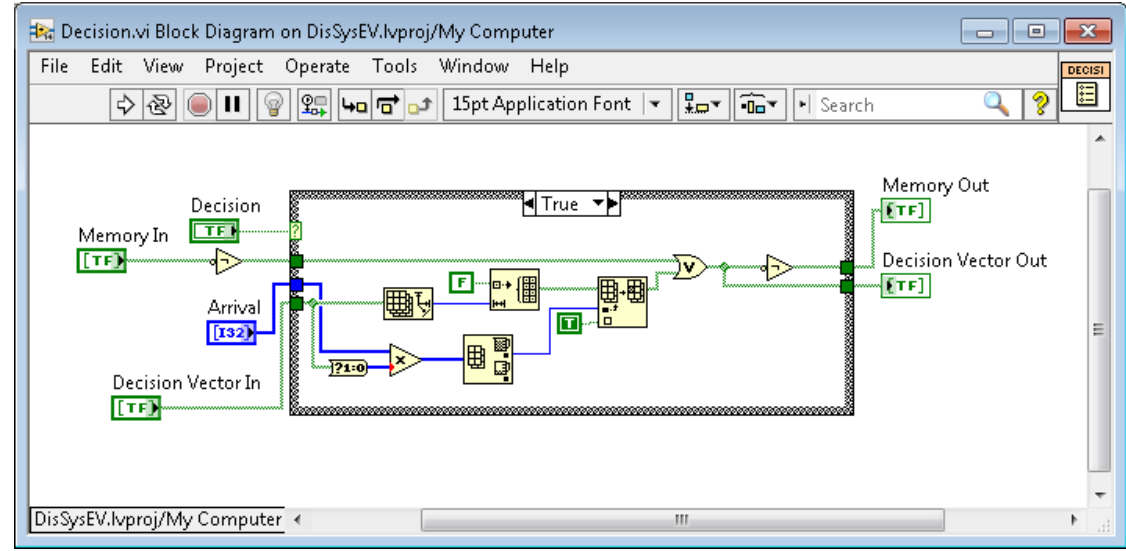

Figure 6: Decision VI

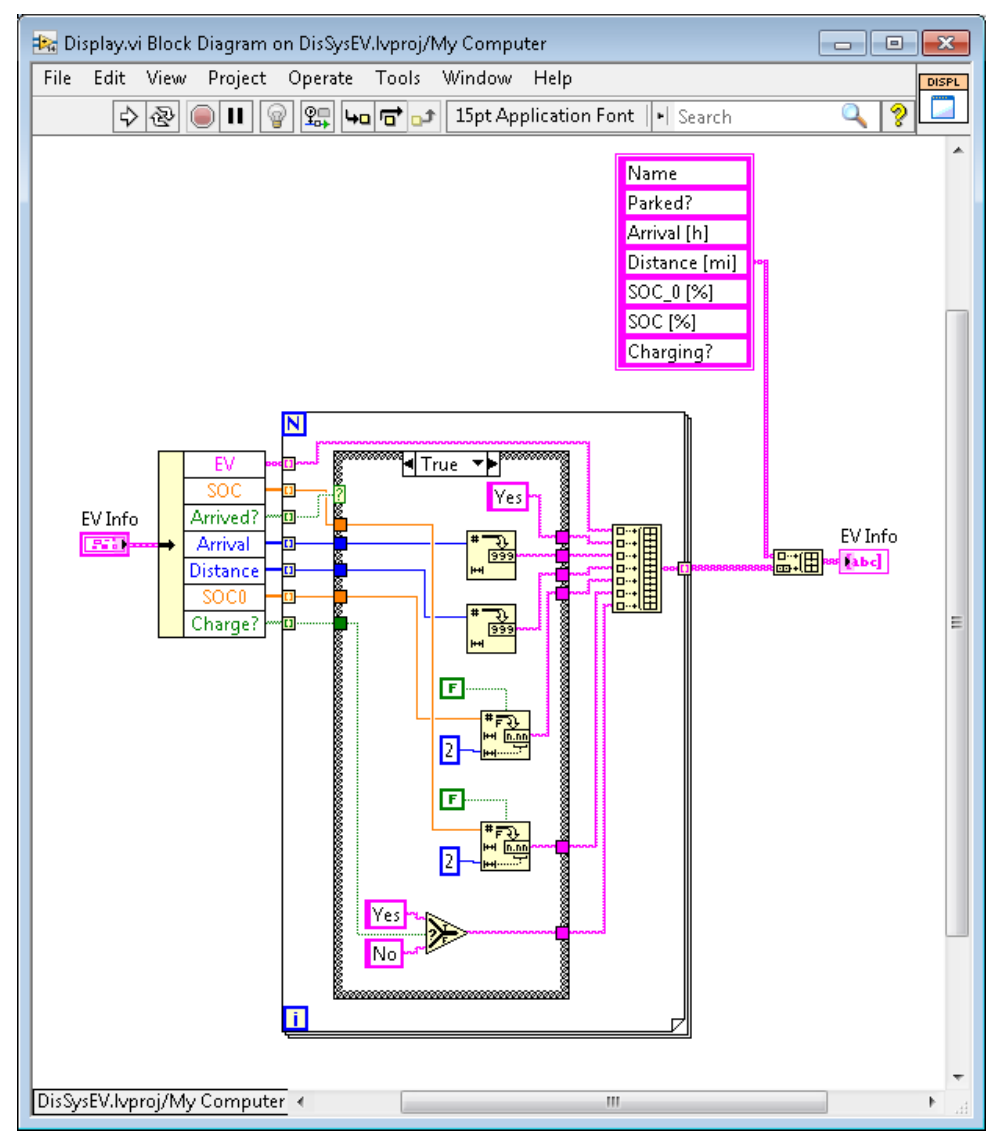

FiguRE 7: Display VI

- Model VI

Sub-VI responsible for generating a complete model for each PEV including arrival time, distance travelled, initial SOC and required charging time.

- Powers VI

Sub-VI responsible for determining if there is an overloading event in the transformers according to the defined limits. 


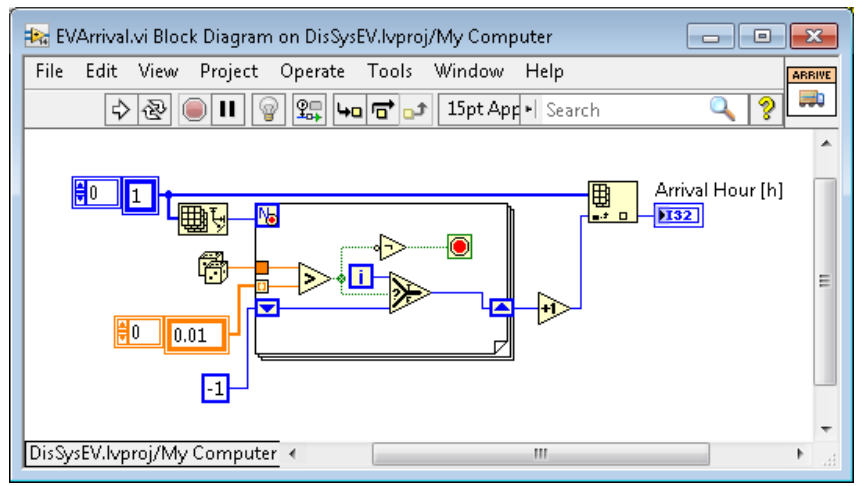

Figure 8: EV Arrival VI

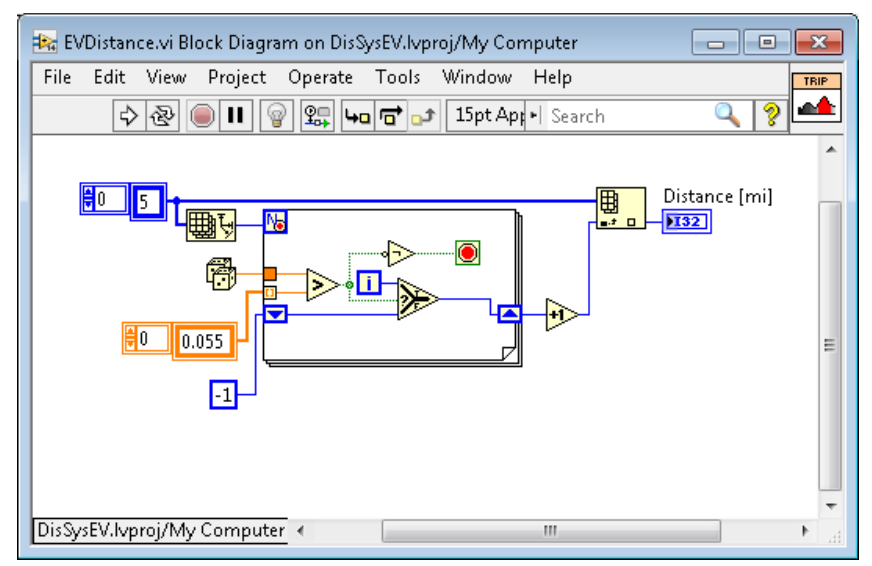

Figure 9: EV Distance VI

- Status VI

Sub-VI responsible for determining if, given the powers of the elements and the voltage at the nodes, there is a violation in the network operation.

- Time VI

Sub-VI responsible for determining if, given a certain simulation time, a PEV must be charging or not (according to the charging scheme).

- Time Adjust VI

Sub-VI responsible for adjusting the simulation time in a 24 hours scale.

- Time Format VI

Sub-VI responsible for adjusting the time format from the string acquired from DSSim-PC to a D-H-M-S basis.

- Voltages VI

Sub-VI responsible for determining if there is a violation in the voltages of the nodes in the PDN, taking into account the operation limit. 


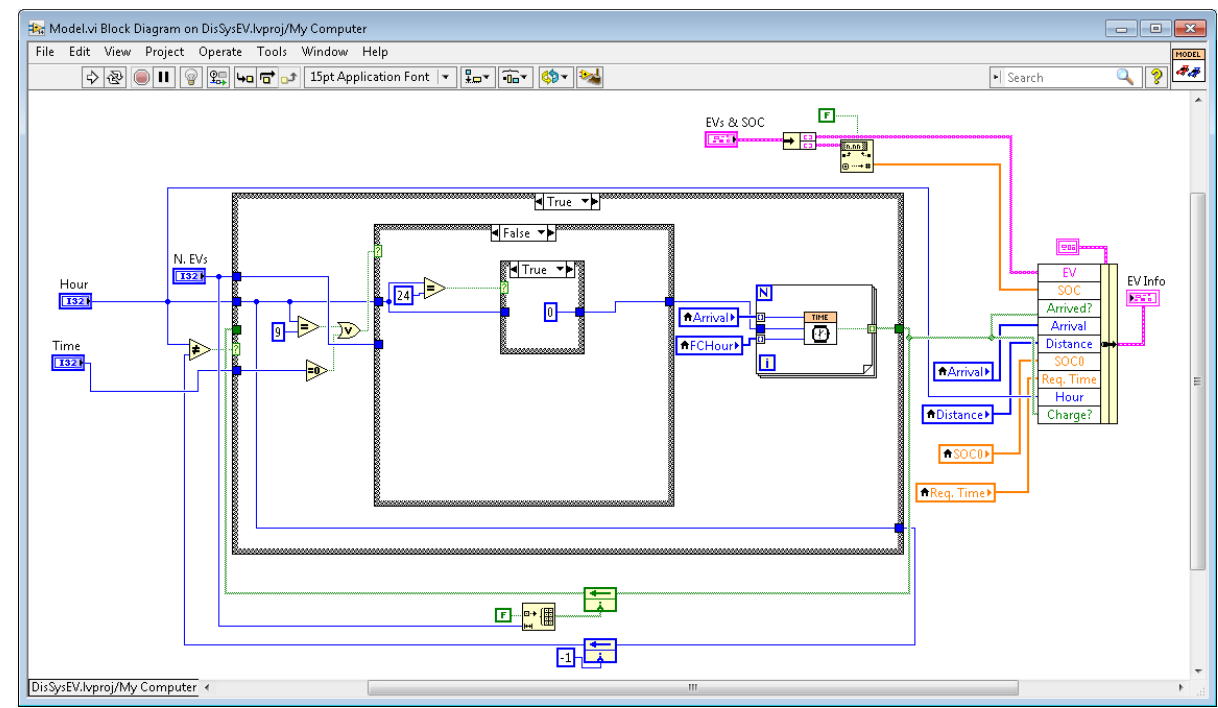

Figure 10: Model VI

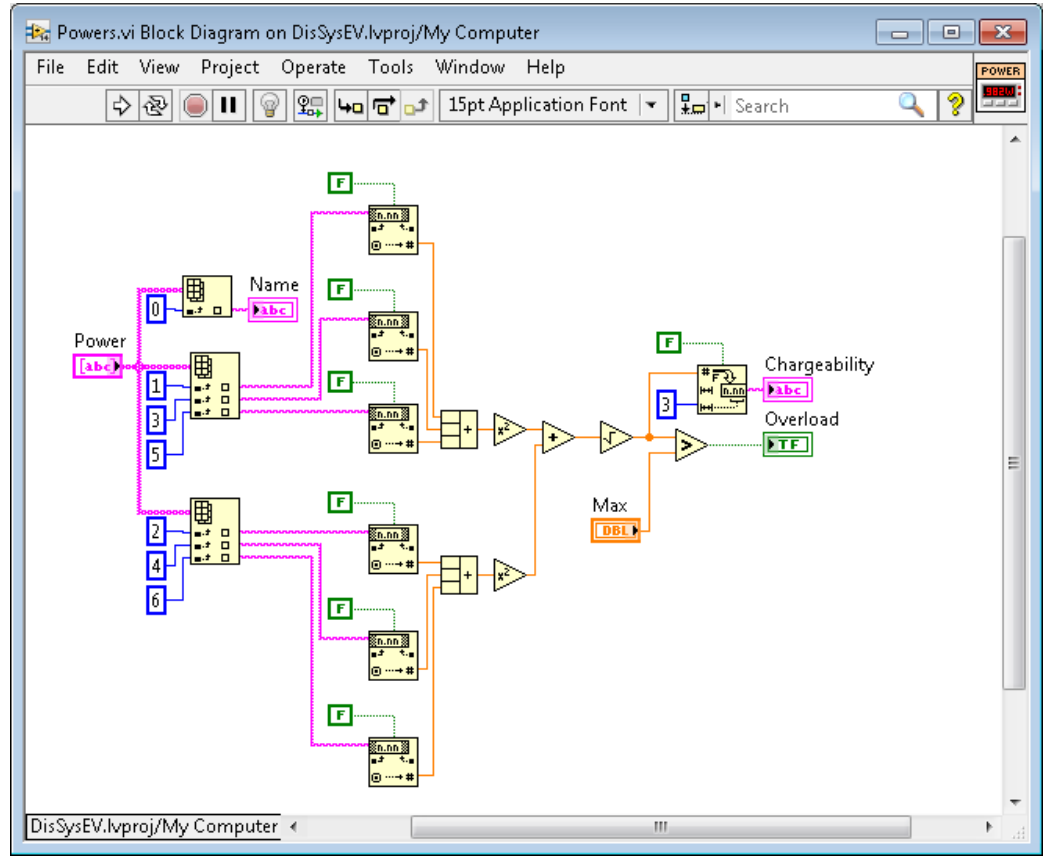

Figure 11: Powers VI

- Write VI

Sub-VI responsible for writing the information from NI LabVIEW to the electrical simulation in DSSim-PC such as when to connect or disconnect PEVs. 


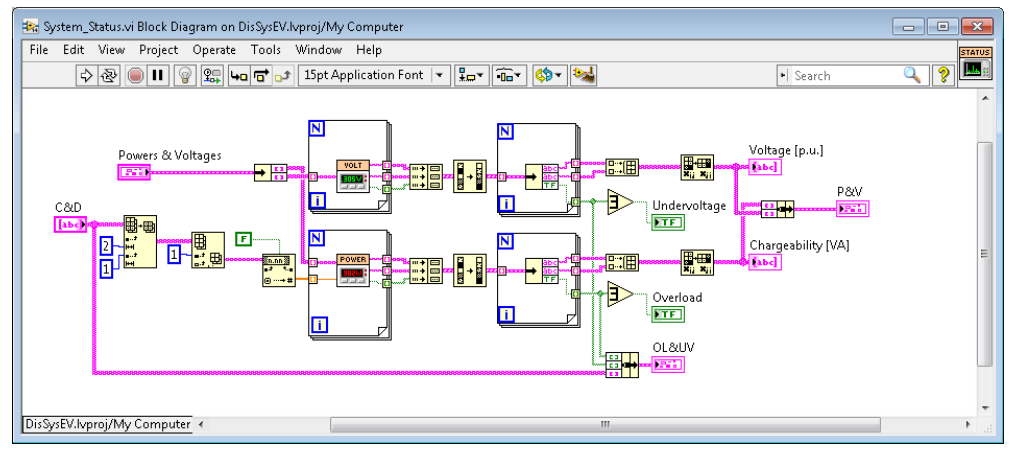

Figure 12: Status VI

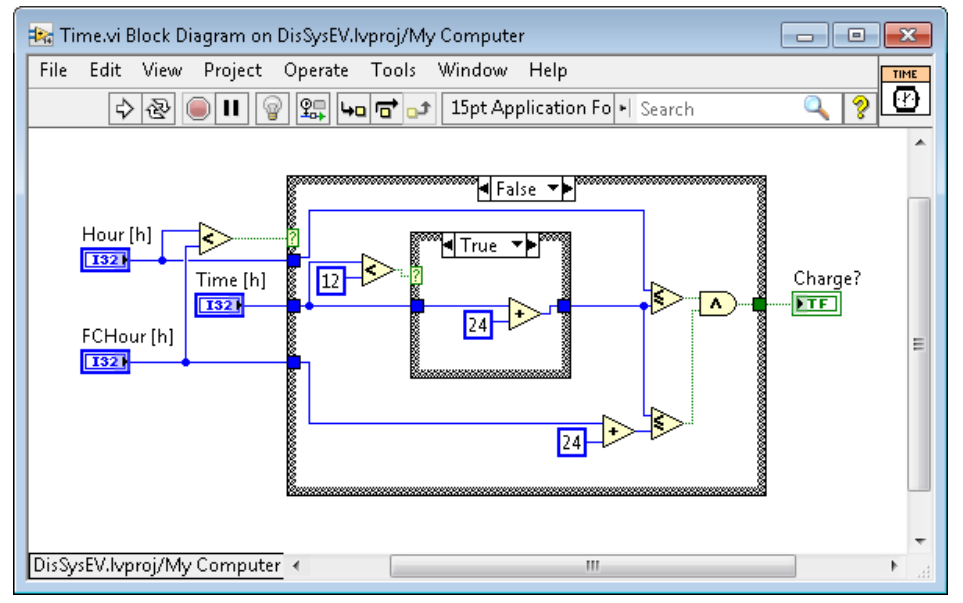

Figure 13: Time VI

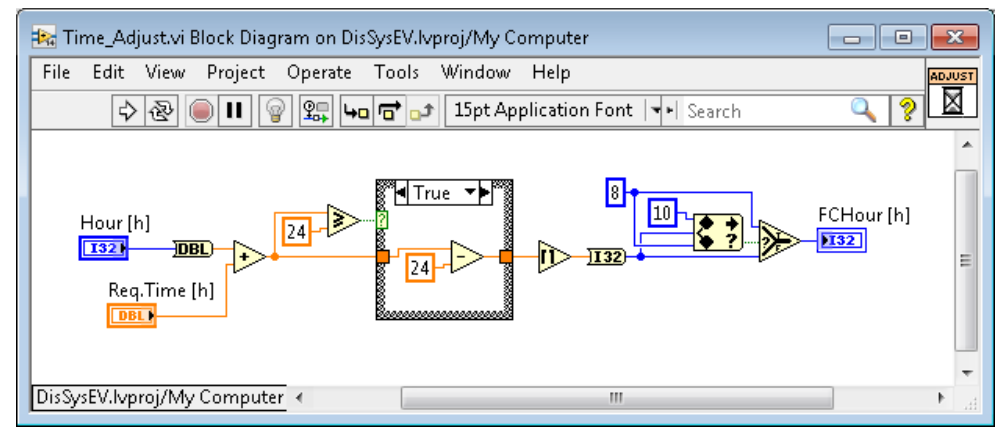

FIgURE 14: Time Adjust VI

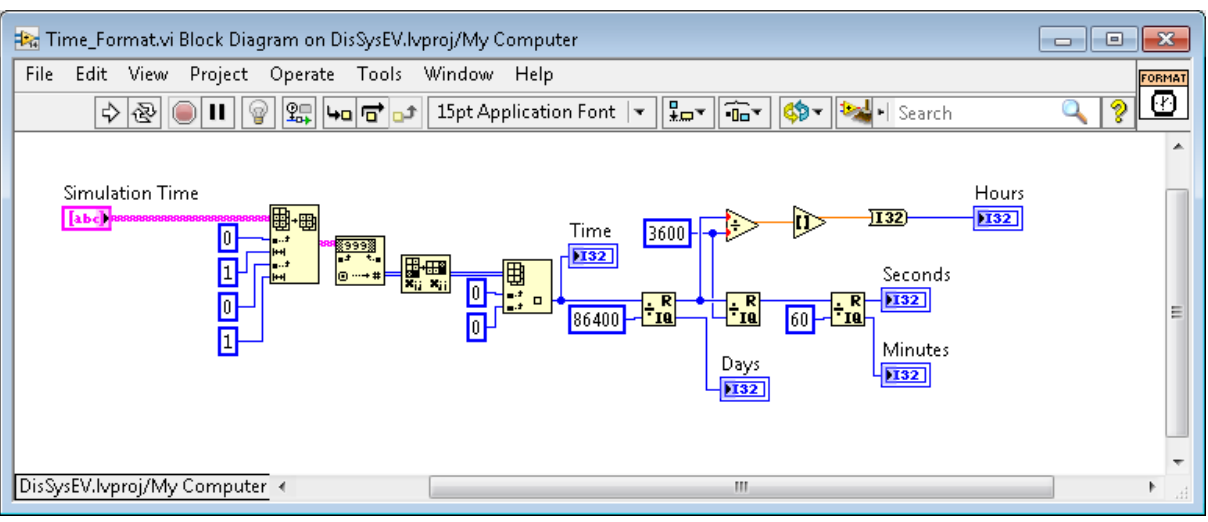

Figure 15: Time Format VI 


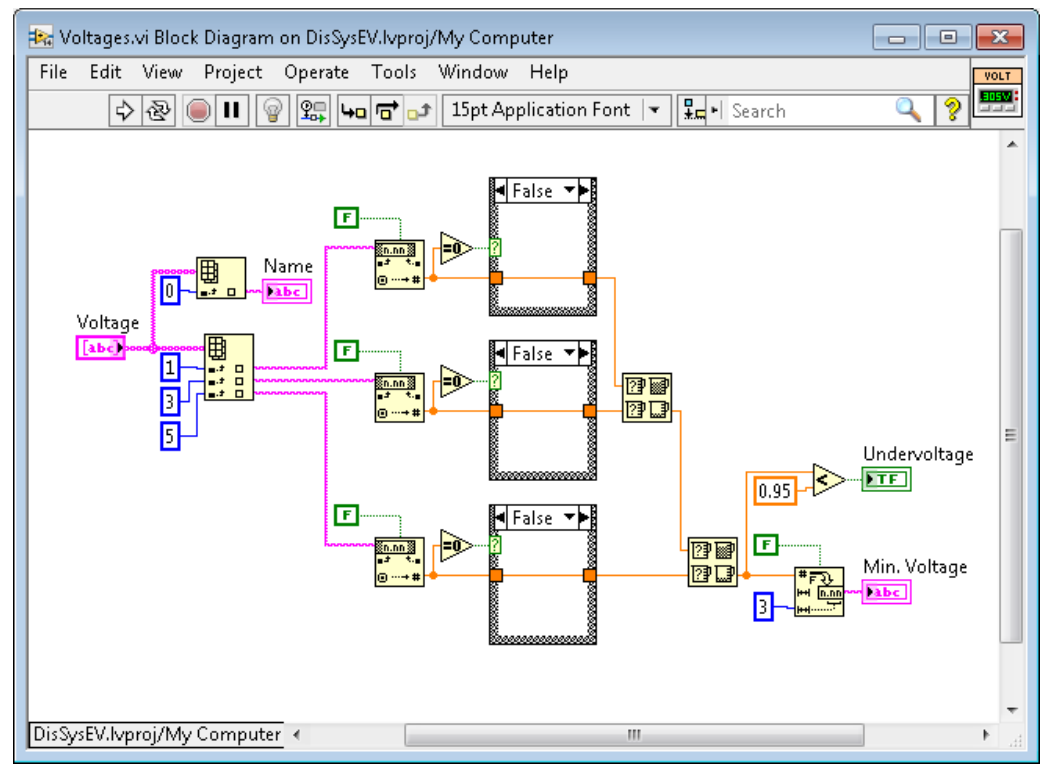

Figure 16: Voltages VI

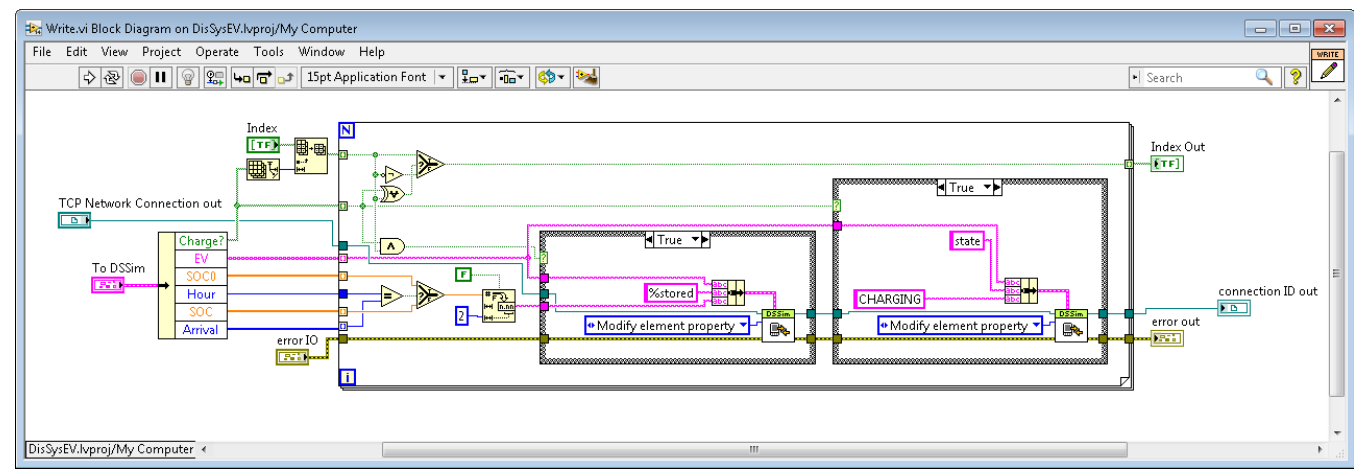

FIgURE 17: Write VI 